\title{
Sistemas de gestión del aprendizaje - Plataformas de teleformación
}

\section{Learning Management Systems}

\author{
Miguel Zapata Ros \\ Universidad de Murcia. España \\ mzapata@um.es
}

\begin{abstract}
Resumen
El presenta artículo constituye una propuesta para el debate y la reflexión sobre la naturaleza y la definición de los sistemas de gestión del aprendizaje. Acerca de cuáles son sus elementos consustanciales y qué funciones pedagógicas puede albergar. Igualmente justifica una propuesta de evaluación de la calidad centrada en el aprendizaje. De esta forma este artículo va unido y sirve para entender y para utilizar una serie de instrumentos para evaluar la calidad de actividades de formación on-line soportadas por estas plataformas, así como las affordances de las plataformas. Los instrumentos se presentan en conjunto con la denominación "Evaluación de un Sistema de Gestión del Aprendizaje"1.
\end{abstract}

\section{Palabras clave}

Calidad, sistemas de gestión del aprendizaje, enseñanza abierta, enseñanza en línea

\begin{abstract}
The present paper constitutes a proposal for the debate and reflection about the nature and the definition of the learning management systems. About which are its inherent elements and what pedagogic functions its can contain. Likewise, it justifies a proposal of evaluation of the quality centered on learning. Thus, this paper is joined and serves to understand and to use a series of instruments to evaluate the quality of activities of on-line formation supported by these platforms, as well as the affordances of the platforms. The instruments appear integrated with the denomination "Evaluation of a learning management system".
\end{abstract}

\section{Key words}

Quality, learning management systems, open education, on-line education.

\section{I}

El siguiente ha de considerarse un documento ${ }^{2}$ que sirva para la reflexión y para la práctica sobre plataformas de aprendizaje a través de redes y otras herramientas

\footnotetext{
${ }^{1}$ Miguel Zapata, 2003. Evaluación de un Sistema de Gestión del Aprendizaje. (42 páginas) http://www.um.es/ead/aula/calidad/plataformas/eval_SGA_beta_1.pdf

${ }^{2}$ En esta versión del artículo se conservan los términos, expresiones, conceptos y marcas tales como fueron formulados en su primera edición en 2003. Todo ha cambiado sustancialmente desde entonces, pero hemos preferido dejarlo tal como se redactó por el valor que puoda tener saber cómo se
} 
asociadas, y para ser utilizado en el seno de actividades de formación que traten estos contenidos. Pero sobre todo ha de ser tenido en cuenta para entender los instrumentos de evaluación de plataformas titulados en conjunto "Evaluación de un Sistema de Gestión del Aprendizaje" ${ }^{3}$ y para una utilización más en consonancia con los objetivos para los que están pensados.

\section{El concepto y los requerimientos básicos}

Se podrían formular distintas conceptualizaciones, haciendo mayor o menor hincapié en ciertos aspectos teóricos, técnicos o formales de lo que es un sistema de gestión del aprendizaje en redes. Incluso de lo pertinente del nombre ----teleformación, e-learning, EAD,...--- o incluso de la actividad, haciendo especial énfasis en las propuestas teóricas subyacentes: Basadas en la cognición, la epistemología, el aprendizaje o las estrategias y las metodologías docentes. Tampoco hay un acuerdo en la delimitación de las funciones que debe cumplir un instrumento de este tipo. Hay quien incluye herramientas por defecto como son las plataformas de trabajo colaborativo, en función de que pueden cumplir la mayoría de los objetivos y funcionalidades que se asignan comúnmente a los SGA, y hay quien incluye por exceso los sistemas de gestión académica porque a veces se les atribuye como valor añadido funcionalidades que son propias de los SGA.

Sin embargo vamos a renunciar a planteamientos de este tipo y vamos a aceptar lo que es común y mayoritariamente aceptado (el mínimo común denominador) en los medios técnicos sin entrar en esa polémica:

Una plataforma de teleformación, o un sistema de gestión de aprendizaje en red, es una herramienta informática y telemática organizada en función de unos objetivos formativos de forma integral [es decir que se puedan conseguir exclusivamente dentro de ella] y de unos principios de intervención psicopedagógica y organizativos, de manera que se cumplen los siguientes criterios básicos

- Posibilita el acceso remoto tanto a profesores como a alumnos en cualquier momento desde cualquier lugar con conexión a Internet o a redes con protocolo TCP/IP.

- Utiliza un navegador. Permite a los usuarios acceder a la información a través de navegadores estándares (como Nestscape, Internet Explorer, Opera,..), utilizando el protocolo de comunicación http.

- El acceso es independiente de la plataforma o del ordenador personal de cada usuario. Es decir utilizan estándares de manera que la información puede ser visualizada y tratada en las mismas condiciones, con las mismas funciones y con el mismo aspecto en cualquier ordenador.

- Tiene estructura servidor/cliente. Es decir permite retirar y depositar información.

conceptualizaban entonces las cosas y las referencias que había a los productos existentes como LMS o equivalentes en ese momento.

3 Miguel Zapata, 2003. Evaluación de un Sistema de Gestión del Aprendizaje. (42 páginas)

http://www.um.es/ead/aula/calidad/plataformas/eval_SGA_beta_1.pdf 
- El acceso es restringido y selectivo.

- Incluye como elemento básico una interfaz gráfica común, con un único punto de acceso, de manera que en ella se integran los diferentes elementos multimedia que constituyen los cursos: texto, gráficos, vídeo, sonidos, animaciones, etc.

- Utiliza páginas elaboradas con un estándar aceptado por el protocolo http: HTML o XML.

- Realiza la presentación de la información en formato multimedia. Los formatos HTML o XML permiten presentar la información, además de en hipertexto, pueden utilizarse gráficos, animaciones, audio y vídeo (tanto mediante la transferencia de ficheros como en tiempo real).

- Permite al usuario acceder a recursos y a cualquier información disponible en Internet. Bien a través de enlaces y las herramientas de navegación que le proporciona el navegador en Internet, bien a través del propio entorno de la plataforma.

- Permite la actualización y la edición de la información con los medios propios que han de ser sencillos o con los medios estándares de que disponga el usuario. Tanto de las páginas web como de los documentos depositados.

- Permite estructurar la información y los espacios en formato hipertextual. De esta manera la información se puede organizar, estructurada a través de enlaces y asociaciones de tipo conceptual y funcional, de forma que queden diferenciados distintos espacios y que esto sea percibible por los usuarios.

- Permita establecer diferentes niveles de usuarios con distintos privilegios de acceso. Debe contemplar al menos: el administrador, que se encarga del mantenimiento del servidor, y de administrar espacios, claves y privilegios; el coordinador o responsable de curso, es el perfil del profesor que diseña, y se responsabiliza del desarrollo del curso, de la coordinación docente y organizativa del curso en la plataforma; los profesores tutores, encargados de la atención de los alumnos, de la elaboración de materiales y de la responsabilización docente de las materias; y los alumnos.

\section{¿Qué problemas vienen a resolver las plataformas?}

Cuando aparecieron las redes telemáticas anteriores a Internet, es decir los videotext (Ibertext, Ibercom, Minitel) y los Bolletin Board System (BBS), fueron aprovechados por ciertas iniciativas, muy minoritarias, pioneras de educación a distancia, diseñándose entornos muy parecidos a los actuales. Con el uso de la mensajería y de la posibilidad de enviar ficheros adjuntos (attachs) o mediante Telnet surge ya la forma de trabajar tan características muy cercanas a lo que hoy se conoce como tutoría telemática , con el uso de los TALK y de las listas de correo se van configurando ambientes muy similares a lo que hoy son las aulas virtuales,... Todo esto señaló un camino y una metodología a seguir muy parecidas a las que posteriormente se organizan con las modalidades de Web Trainning. 
Posteriormente con la generalización de Internet, como red universitaria primero y de interés general después, los profesores que utilizan los servicios de la red para uso académico, para trabajo colaborativo, para intercambiar informaciones y documentos, en el seno de sus núcleos de investigación, centros, departamentos,... empiezan a observar, a medida que se van sintiendo seguros en el uso de los servicios y herramientas, que ciertos usos y servicios facilitan una singular forma de trabajar en sus entornos. Y esto sucede cuando trabajan en educación a distancia, con las características propias de la educación a distancia, y cuando trabajan de forma presencial como complemento a sus estrategias docentes y tutoriales habituales. Realmente es por ahí por donde comienza la proliferación de usos instruccionales de la red. La convergencia se produce pues desde abajo, desde el trabajo colaborativo, hacia las modalidades de apoyo a la tutoría basado en redes, sea presencial o a distancia. Este hecho avanza en la medida que se va produciendo la incorporación de los alumnos a las redes, tanto desde sus domicilios como desde las Aulas de Libre Acceso (ALAs). Naturalmente la formación a distancia de postgrado se ve notablemente favorecida por la capacidad económica y de acceso a las redes de estos usuarios.

Es la práctica pues la que va decantando los usos de los servicios de Internet. Así se configuran los entornos que ya hemos citado de tutoría telemática, con apoyo de mensajería y de envíos de adjuntos, los FTP como repositorios de materiales (apuntes, documentos de referencia, artículos colecciones de ejercicios, prácticas, problemas,...) y los debates en foros asíncronos pero sobre todo en listas de discusión.

La unidad y la cohesión la prestan las páginas y los sitios webs de los cursos y también de los profesores individuales.

De esta forma algunas universidades más dinámicas y más responsables de su compromiso con la comunidad de aprendizaje ---Universidad de Cornell con BlackBoard (http://www.blackboard.com/worldwide/es/es/index.htm ), University of British Columbia (Canadá) con Web CT (http://www.umass.edu/webct/instructor/about/ history.html),... ---en algunos casos y asociaciones de profesores en otros --- US WEST Foundation, vinculada a la National Education Association, a través de Washington Education Association, para el caso de Learning Space (http://www.learningspace.org/ about/history.html )--- lo único que hacen es dar cuerpo como herramienta informática a estos entornos basados en la red, eso sí apoyados por potentes equipos de psicopedagogos que estudian, estudian y diferencian, las operaciones, funciones y perfiles en presencia, y apoyados sobre todo por equipos de técnicos informáticos, programadores que dan cuerpo mediante aplicaciones informáticas a estos entornos y a los sistemas de operaciones y procedimientos asociados. De esta manera surgen las plataformas, no como un ejercicio teórico o técnico aislado de la práctica sino como una consecuencia de ella. Culminando con ello el proceso que se había abierto antes con la práctica.

Por último son consorcios o empresas más o menos vinculadas a estas universidades o centros de investigación las que perfeccionan los productos, los comercializan y los distribuyen.

\section{¿Qué espacios y qué funciones se generan y con qué características?}

A veces las plataformas nacen teniendo como referencia las enseñanzas presenciales y metáforas sugerentes pero poco efectivas o poco vinculadas a los problemas reales que 
la distancia y el aprendizaje plantean. Otras veces las plataformas nacen teniendo en cuenta exclusiva o preferentemente la reprersentación conceptual, o cognitiva, que de ellas se hacen los técnicos, los informáticos o los programadores, ... o los técnicos en comunicación. Son ideas implícitas centradas en el medio o en la herramienta, o en la gestión o en la publicidad.

Si partimos del análisis de lo que puede hacerse en Internet más las estrategias y metodologías docentes asociadas tenemos que hablar de

\section{Análisis desde el punto de vista del servicio o de la herramienta}

*Como:

+ ¿Qué metodologías son las más eficientes?

+ ¿Qué características ha de tener?

$+¿$ Qué ventajas ofrece sobre cualquier otra estrategia? 


\section{Análisis de herramientas y servicios}

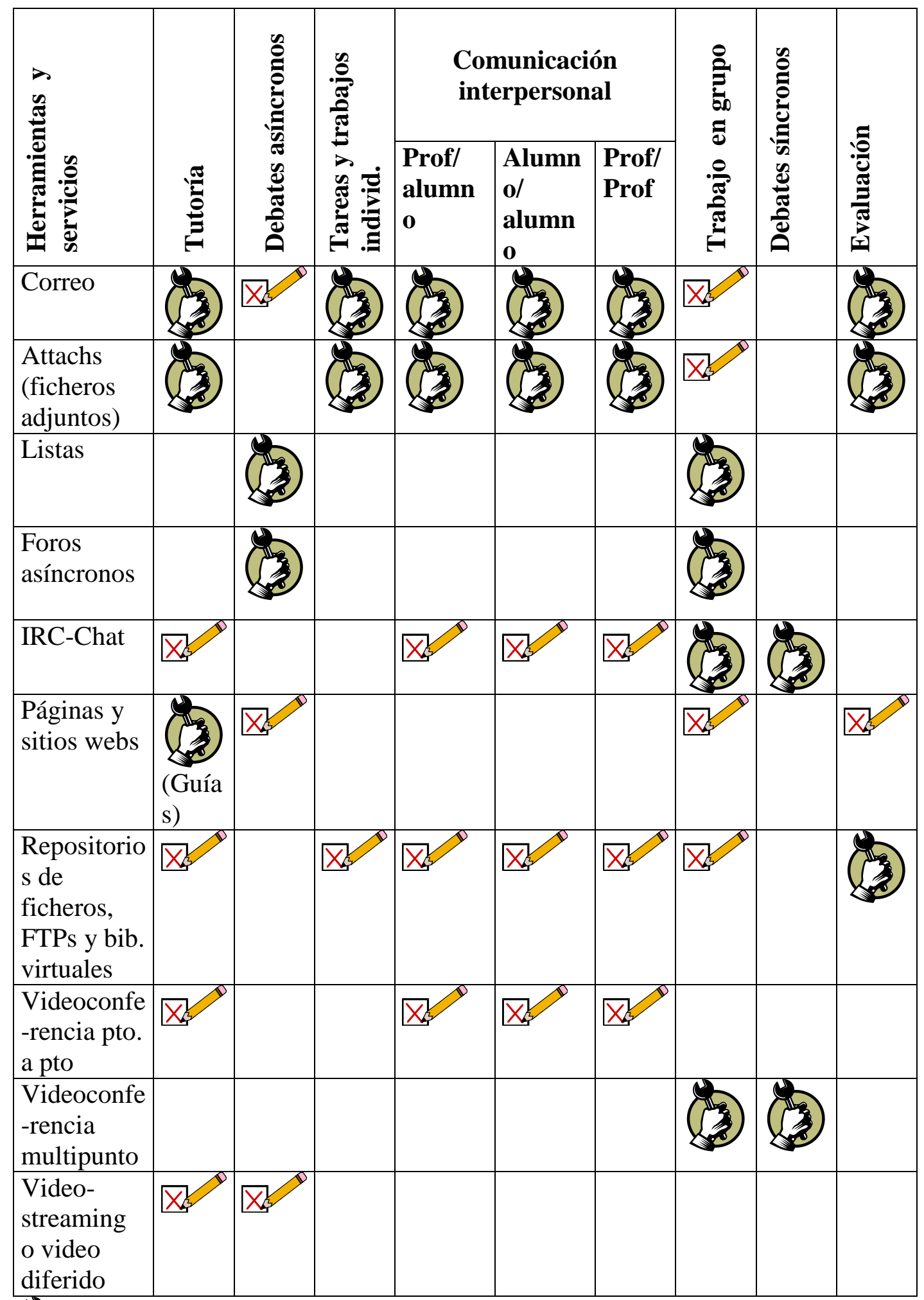

diferido

: Herramienta o servicio principal

: Herramienta auxiliar 


\section{Análisis desde el punto de vista de la función}

\section{*Como:}

+ ¿Qué herramientas son las más indicadas para determinada función pedagógica o instruccional?

+ ¿Qué características ha de tener?

$+¿$ Qué ventajas ofrece sobre cualquier otra herramienta o servicio?

Una posible distribución sería la que establecemos a partir de la propuesta que hace Bárbara de Benito (De Benito, 2000) ${ }^{4}$ con variaciones debidas a los cambios introducidos desde su formulación y otras debidas a distintas conceptualizaciones:

\begin{tabular}{|c|c|c|}
\hline Función & Utilidades & \\
\hline $\begin{array}{l}\text { Comunicación/información } \\
\text { compartida/trabajo } \\
\text { cooperativo }\end{array}$ & grupo & $\begin{array}{l}\text { Correo electrónico } \\
\text { Ficheros adjuntos. } \\
\text { Repositorios de ficheros } \\
\text { Audioconferencia } \\
\text { Chat } \\
\text { Pizarra compartida } \\
\text { Navegación cooperativa } \\
\text { Videoconferencia } \\
\text { Transferencia de ficheros } \\
\text { Bookmarks, } \\
\text { Marcadores/favoritos } \\
\text { Espacios de trabajo en }\end{array}$ \\
\hline Administración docente & $\begin{array}{l}\text { de los } \\
\text { de }\end{array}$ & $\begin{array}{l}\text { Permisos de Inscripción } \\
\text { alumnos. } \\
\text { Gestión de alumnos: } \\
\text { Elaboración de fichas y } \\
\text { listas } \\
\text { Privilegios de } \\
\text { acceso/seguridad } \\
\text { Consulta expediente } \\
\text { académico }\end{array}$ \\
\hline
\end{tabular}

\footnotetext{
${ }^{4}$ Bárbara de Benito Crosetti, 2000. Herramientas para la creación, distribución y gestión de cursos a través de Internet. Edutec. Revista Electrónica de Tecnología Educativa. Núm. 12.
}

/junio 2000 


\begin{tabular}{|c|c|c|}
\hline $\begin{array}{l}\text { Gestión/desarrollo del } \\
\text { curso/evaluación }\end{array}$ & $\begin{array}{l}\text { de los } \\
\text { pruebas y } \\
\text { evaluación y }\end{array}$ & $\begin{array}{l}\text { Seguimiento y progreso } \\
\text { alumnos } \\
\text { Informes y estadísticas } \\
\text { Calendario } \\
\text { Gestión y edición de } \\
\text { de ejercicios de } \\
\text { de autoevaluación } \\
\text { Diseño del curso } \\
\text { Portafolio }\end{array}$ \\
\hline $\begin{array}{l}\text { Interacción/contenidos de } \\
\text { aprendizaje }\end{array}$ & $\begin{array}{l}\text { de } \\
\\
\text { utilidades }\end{array}$ & $\begin{array}{l}\text { Anotaciones } \\
\text { Notificación automática } \\
\text { cambios } \\
\text { Referencias } \\
\text { Bases de datos } \\
\text { Creación de materiales } \\
\text { Indices alfabéticos } \\
\text { Creación de itinerarios } \\
\text { Indexación } \\
\text { Glosario } \\
\text { Interconexión entre }\end{array}$ \\
\hline
\end{tabular}

Espacios virtuales básicos en un sistema de gestión del aprendizaje en redes (eSGA) ${ }^{5}$

\section{Los espacios}

\section{El espacio virtual docente o aula virtual}

El espacio virtual docente es donde se realiza propiamente la actividad educativa, y está constituido por los espacios y servicios que sirven directamente a ese fin. La base común está constituida por informaciones hipertextuales colocadas en el espacio web correspondiente al aula virtual, y es donde están las guías didácticas y las guías de recursos, además de todas las informaciones necesarias para el desarrollo de la actividad docente. desde allí se tiene acceso al resto de espacios constituidos por foros bien en plataformas de teleformación en listas de distribución, etc. De una u otra forma podemos encontrar tres espacios:

\footnotetext{
${ }^{5}$ Formación abierta y a distancia a través de redes digitales: Modelos de redes de aprendizaje. RED núm. 1, Págs. 9-10. M. Zapata http://www.um.es/ead/red/1/modelos.pdf
} 


\section{El espacio de atención personal (la tutoría virtual)}

Lo más sencillo es dar soporte a la atención personal a través de mensajería electrónica y FAQs en el espacio web del aula virtual. Sin embargo las plataformas de teleformación disponen, además de un servicio de mensajería integrado, un espacio público el tablero del profesor o tablón de anuncios, que es un espacio al que solo tiene acceso el tutor para anunciar convocatorias, dar informaciones o presentar propuestas a los alumnos. Entre ambas cosas, mensajería con envío y recepción de ficheros adjuntos y tablón de anuncios se produce la tutoría telemática que será tanto más completa cuanto mayor sea la interacción.

\section{El espacio de debate}

Habitualmente se articula sobre una lista de discusión y la correspondiente base de datos de mensajes a la lista, o bien sobre una lista integrada en la plataforma del campas.. En él tiene lugar los debates propuestos sobre temas de la materia por el tutor con un guión establecido en la guía de la materia. Este espacio genera una actividad de gran potencial de aprendizaje: Los debates con una metodología propia.

Estos debates son coordinados por el tutor, de manera que concurren él la tripe condición de tutor, animador-moderador del debate y administrador de la lista.

\section{El foro}

El foro es el espacio común, no estrictamente curricular, compartido por el tutor y todos los alumnos adscritos a la misma materia. En él se tratan todos los temas grupales que no tiene que ver estrictamente con el desarrollo de los contenidos. Además es donde se expresan opiniones sobre la materia, la marcha del curso, los materiales. Es un espacio más abierto que el espacio de debate, se puede articular sobre una lista, o en algunos casos sobre un chat. Puede también cumplir el papel del tablero del profesor de manera que en él se comuniquen convocatorias, etc. En cualquier caso es el espacio donde se cobra conciencia de comunidad virtual. o de comunidad de grupo de clase virtual.

\section{El espacio virtual de la información, la biblioteca virtual , el FTP,...}

En los proceso de formación abiertos y a distancia es de especial importancia disponer de un acceso rápido, flexible y organizado a la información que se utilice, tanto a la información del curso, las documentaciones, las guías, las fichas y cuestionarios de las actividades así como a una amplia gama de información bibliográfica propia o remota en Internet. este es el objetivo de las bibliotecas virtuales, bases de datos de documentos y FTPs adscritos al espacio de docencia y con enlaces desde él.

Cuando el acceso es difícil o remoto el papel del espacio de información virtual puede ampliarse con otros recursos que soporten la información digitalizada: CD-ROM, DVD, etc. que se envíen a los alumnos o que se depositen en los centros locales. 


\section{II}

\section{Funciones pedagógicas}

El análisis de las funciones pedagógicas de un entorno presencial implica una explicitación superior a lo que ocurre en las plataformas. El uso de estas herramientas y su análisis pone de relieve un sistema más complejo pero más explícito de funciones. Entre las que hemos podido detectar que en parte coinciden con las que la literatura especializada contempla (Marcelo, 2001 ${ }^{6}$, Marcelo $2002^{7}$ y De Benito, 2000 ${ }^{8}$ ) podemos ver:

Propuesta de itinerario formativo. A través de la plataforma el alumno puede diseñar según sus expectativas e intereses los cursos, materias, seminarios u otras acciones formativas así como la secuencia de ellas. El sistema debe de ir provisto de itinerarios conformados, así como de criterios de articulación: incompatibilidades, requisitos, orientaciones, pautas, etc.

Propuesta de guía curricular. A través de la plataforma los tutores, coordinadores, y demás docentes implicados proponen objetivos formativos, establecen el conjunto de actividades $\mathrm{y}$ tareas precisas para conseguirlos, los criterios y herramientas de evaluación, así como los procedimientos para evaluar o autoevaluar, también proponen los recursos y la distribución temporal para todo ello.

Apoyo en la formación. Nos referimos fundamentalmente a apoyo documental y a recursos formativos: Ejercicios, prácticas, guías didácticas, documentos y textos bases (planos y multimedia), pero también a cualquier otro tipo de apoyo (apoyo multimedia, apoyo experto,...) en recursos como de comunicación, técnicas de estudio y de trabajo intelectual, ayuda de navegación etc.

Seguimiento del progreso del estudiante. Nos referimos a todas aquellas opciones y operaciones que proporcionan diferentes tipos de información al profesor, y que le permiten realizar un seguimiento sobre el progreso del alumno. Esta información puede

\footnotetext{
${ }^{6}$ Marcelo, C. Puente, D., Talavera, C. y Torres, J. (2001). Formando Teleformadores: Diseño y desarrollo de un curso online utilizando Webct. Comunicación presentada a la II Conferencia Internacional de Tecnologias de Informaçao e Comunicaçao na Educaçao, Braga, Portugal http://prometeo.us.es/idea/mie/pub/marcelo/Formando\%20Teleformadores.pdf , 02/07/03 11:37

${ }^{7}$ Marcelo, C. et al. (2002). E-Learning Teleformación. Diseño, Desarrollo y Evaluación de la Formación a Través de Internet. Barcelona, Editorial Gestión 2000

${ }^{8}$ Barbara de Benito Crosetti, Herramientas para la creación, distribución y gestión de cursos a través de Internet
}

Edutec. Revista Electrónica de Tecnología Educativa. Núm. 12. /junio 2000

http://edutec.rediris.es/Revelec2/Revelec12/deBenito.html 
provenir de los resultados de ejercicios y de las tareas propuestas, de los test de autoevaluación realizados por los estudiantes, de las estadísticas sobre los itinerarios seguidos y de los accesos practicados en los materiales de aprendizaje, de la participación de los alumnos a través de herramientas de comunicación (mensajes enviados, participación en debates y calidad de las intervenciones,...), número de veces que ha accedido el alumno al sistema, tiempo invertido, etc. todas ellas son viables, es decir actualmente existen dispositivos que las generan automáticamente. Algunas herramientas además de generar estadísticas generan gráficas de los aspectos reseñados.

Comunicación interpersonal. Metodológicamente es el aspecto más importante y definitorio de una plataforma. Esta función constituye uno de los pilares fundamentales dentro de los entornos de aprendizaje en redes, ya que posibilita el intercambio de información, el diálogo y la discusión entre todas las personas implicadas en el proceso y sobre todo las condiciones en que se produce. En función del diseño del curso, y de la plataforma hay distintas formas de integrar aplicaciones de comunicación interpersonal (a veces como herramientas ad hoc, desarrolladas por el propio sistema, y cada vez con más frecuencia por herramientas estándares que el usuario ya utiliza en la vida real, así sucede con el correo POP-3 por ejemplo) como son el correo electrónico, listas, chat, foros, ... Esta aplicaciones se pueden clasificar según el criterio de concurrencia en el tiempo en síncronas (audio/videoconferencia, pizarra electrónica, espacios virtuales, chats...) y asíncronas (correo electrónico, noticias, tablero electrónicos...) o, según el criterio de concurrencia personal, en aplicaciones punto a punto (correo, videoconferencia RDSI,...) o multipunto (listas, chat, videoconferencia VRVS, foros,...)

Trabajo colaborativo. Las plataformas incorporan entornos particulares que permiten el trabajo colaborativo entre los alumnos (o entre profesores). Estos entornos posibilitan compartir información, elaborar, modificar, adicionar,... documentos conjuntos,... mediante facilidades de programación que establecen actualizaciones simultaneas, diferentes versiones,... Esta modalidad de trabajo facilita y entrena para la solución de problemas, la toma de decisiones, el trabajo en grupo, etc.

Además de los entornos de este tipo que integran las plataformas hay herramientas que están pensadas únicamente con este fin. Son las plataformas de trabajo colaborativo. En este caso estos programas llevan opciones específicas orientadas al trabajo cooperativo, como son: transferencia de ficheros (FTPs), aplicaciones compartidas; calendario, chat, convocatoria de reuniones, lluvia de ideas, mapas conceptuales, navegación compartida, notas, pizarra compartida, videoconferencia, ... El más conocido de ellos es BSCW.

Creación de ejercicios de evaluación y autoevaluación. Como ya hemos señalado otras veces la evaluación de los aprendizajes, no solo en este tipo de entornos, debe ser vista desde dos perspectivas diferentes. Por una parte, la clásica desde el punto de vista del profesor. Ésta le proporcionará informaciones sobre el proceso en la adquisición de conocimientos y destrezas por parte del alumno y también sobre la efectividad del diseño, y sobre el desarrollo, de todo el sistema de formación. La otra perspectiva es la del alumno, la percepción del alumno acerca de su propio progreso se produce a través de ejercicios de autoevaluación. Mediante ellos, o basándose en ellos, recibe 
informaciones y /orientaciones sobre el grado y la calidad de los conocimientos adquiridos.

Las plataformas habitualmente van provistas de herramientas que posibilitan diferentes tipos de ejercicios: de respuesta múltiple, de relación, ejercicios cloze, de respuestas booleanas (verdadero/falso, si/no,...), observación visual, etc. y de ejercicios abiertos que puede contrastarse con otros ejercicios de plantilla.

Acceso y procesamiento de información y de contenidos de aprendizaje. Las plataformas constituyen parte de eso tan complejo y tan extenso que hemos dado en llamar la sociedad de la información y del conocimiento. Y como tal participa de algunas de las características más importantes de aquella. En este caso se trata de acceder a las ingentes cantidades de información que hay en las redes y a la posibilidad de proceso de esa información obteniendo conocimientos de ella. En particular y específicamente las plataformas proporcionan acceso a recursos singulares de aprendizaje: hipermedias, simulaciones, textos digitales (en diferentes formatos), imágenes, esquemas, ficheros de vídeo o de audio, listas de ejercicios, enunciados y desarrollo de prácticas, tutoriales, glosarios, etc. Además las plataformas mediante guías de recursos y relaciones de enlaces permiten a los alumnos acceder a grandes cantidades de información especializada a través de los múltiples repositorios disponibles en Internet como: bases de datos on-line o bibliográficas; sistemas de información y buscadores temáticos; libros digitales, informaciones en vídeo, audio, videoclips; publicaciones electrónicas; centros de interés (bibliotecas y museos digitales,...), enciclopedias, diccionarios, traductores,,..

Interacción. La comunicación interpersonal es estéril si no va acompañada de la capacidad de modificar e intervenir en los procesos cognitivos y en e cambio de actitudes de los otros y los otros en las nuestras. Es decir sin interacción.

En los entornos de enseñanza basados en la web podemos diferenciar al menos cuatro niveles de interacción entre: profesor-alumno, alumno-alumno, alumno-contenidos de aprendizaje y profesor-profesor. A diferencia de cómo sucede en otras funciones, no hay herramientas asociadas a esta función: Se produce o no se produce en todas, aunque va vinculada especialmente a algunas: Correo, listas,... No obstante un elemento de calidad es la posibilidad que presentan algunas plataformas de tener diferentes utilidades vinculadas a herramientas como es el portafolio, el correo electrónico vinculado con la gestión de alumnos y los resultados de los ejercicios de evaluación, de forma que el profesor puede enviar mensajes individuales a los alumnos en función de las respuestas y el procedimiento de resolución o del resultado de un ejercicio propuesto.

Gestión y administración educativa de los alumnos. No consideramos aquí los entornos de gestión administrativa de la formación a través de redes, que permiten llevar a cabo todas aquellas actividades relacionadas con la gestión académica de los alumnos como son matriculación, consulta del expediente académico y de las calificaciones, expedición de certificados,... que constituyen capítulo aparte, que deberían tener en cuenta criterios y requisitos procedentes del análisis de los objetivos formativos, y que frecuentemente no solo se lo saltan sino que los afectan.

En este punto de lo que hablamos es de las funciones, de organización y gestión de los alumnos y de los grupos, que tienen que ver en cómo se organiza la enseñanza, el aprendizaje, los recursos y la evaluación. 
Por ejemplo hablamos de la elaboración de grupos, de horarios, de calendarios, pero sobre todo de funciones que afectan nuclearmente a la gestión del proceso de enseñanza-aprendizaje, como son establecer privilegios de acceso, con la importancia que tiene en la creación modificación de roles y perfiles docentes, la creación de grupos, el acceso a la información sobre alumnos, la creación de listas y plantillas para seguir y evaluar el progreso en el aprendizaje, la elaboración, diseño y gestión de espacios, etc.

\section{Herramientas para la gestión de la formación a través de redes}

Basándonos y tomando en cuenta la propuesta de clasificación de McGreal, $R$., Gram, T.y Marks, $T$ (2003) $)^{9}$, TéléÉducation NB (2003) ${ }^{10}$, Chris Smith, Terry Murphy y Tricia Teng $(2001)^{11}$, a través de De Benito, Barbara (2000) ${ }^{12}$ vamos a categorizar los tipos de herramientas que se utilizan para la gestión de la formación a través de redes.

Centraremos pues la cuestión en la gestión del aprendizaje, de la enseñanza y de la intervención docente y organizativa. En consecuencia dejamos de lado, aunque lo reseñemos, la gestión administrativa por mor de señalar las condicionantes de lo psicopedagógico en lo administrativo en un sistema centrado en el alumno.

1. Editores de cursos y otros programas para la creación de materiales de aprendizaje multimedia. Incluimos en este grupo todas aquellas herramientas que se utilizan para la edición de contenidos de aprendizaje en formato multimedia. Incluimos:

a. los composers o editores de páginas web (aunque no está claro que deban incluirse en este apartado, como son utilizados con este fin creemos adecuado incluirlos. Sirven para crear páginas webs que cohesionan y organizan la información y los elementos de los cursos, integran diferentes elementos multimedia y enlaces hipertextuales, materiales curriculares, como son guías didácticas y propuestas de actividades, o manuales hipermedia,...);

\footnotetext{
${ }^{9}$ McGreal, R., Gram, T.y Marks, T.: A Survey of New Media Development and Delivery Software for Internet-Based Learning. [http://telecampus.com/developers/environment/index.html] [http://www.eduworks.net/Webnet2000/newmedia.ppt 25/06/03 12:38]

${ }^{10}$ TéléÉducation NB, 2003

Plates-formes de formation en ligne http://teleeducation.nb.ca/content/e-learning-environments/plates-formes/index.html 25/06/03 $12: 43$

${ }^{11}$ Chris Smith, Terry Murphy y Tricia Teng (2001). The Perfect Fit: Selecting the Online Learning Environment of Tomorrow. Consortium for Information Technology in Education (CITE). New Brunswick Community College - Saint John Today. April 2001
}

${ }^{12}$ Barbara de Benito Crosetti, Herramientas para la creación, distribución y gestión de cursos a través de Internet

Edutec. Revista Electrónica de Tecnología Educativa. Núm. 12. /junio 2000 
b. los programas de autor: Son herramienta especialmente diseñadas para crear cursos multimedia, y tienen opciones para ello. Facilitan la confección de aplicaciones multimedia interactivas que pueden ejecutarse en Internet a través de 'plugins' o "applets" y

c. los programas que permiten la creación de ejercicios de autoevaluación, simulaciones, etc.

Ejemplos:

Composers o editores páginas web:

- Page Mill

- Home Page

- Dreamweaver/Course Builder

Programas de autor:

- Authorware Professional (Macromedia)

- Quest Net+ (Allen Communication)

- IconAuthor (Aim Tech Corp)

- Toolbook (Asymetrix)

- Director (Macromedia).

Programas de creación de ejercicios:

- Quizmaker

- QuestionMark

- Qform

- QuizCode

2. Programas para la comunicación y el trabajo colaborativo, plataformas de trabajo colaborativo. Nos referimos a aquellas herramientas que permiten a un grupo comunicarse en el desarrollo de un proyecto o actividad común y elaborar un producto conjunto.

Este tipo de herramientas son de tipo asíncrono por lo general aunque pueden ir provistas de servicios síncronos como el chat. Se utilizan en todos los ámbitos donde se trabaja cooperativamente (estudios, gabinetes, grupos de investigación,...) En el tipo de actividad a la que va referido este trabajo la comunicación y la colaboración se establece entre: alumno-profesor o alumno-alumno.

Estos programas raramente contienen una sola utilidad (como correo electrónico, chats,..) casi siempre contienen repositorio de ficheros con utilidades de actualización y edición conjunta así como conferencias electrónicas, audioconferencias, videoconferencia, pizarra compartida, aplicaciones compartidas o documentos compartidos.

Entre este tipo de herramientas las más conocidos o utilizados son

- $\mathrm{BSCW}$,

- Allaire Forum,

- Alta Vista Forum, 
- Backtalk,

- CaMILE,

- Caucus,

- CDboard,

- ClassAct,

- ClassPoint,

- COSE,

- Centra Symposium,

- FirstClass,

- FORUM,

- iClass,

- Mayetic Village,

- LearnLinc,

- TOBACO.

4. Plataformas de teleformación.- Son herramientas integradas para la creación e impartición de cursos a través de Internet. Estás desarrolladas específicamente con propósitos educativos o formativos. Son aplicaciones de Internet que pueden soportar entornos de aprendizaje en redes, y que integran, en función de su potencia, de su grado de desarrollo y de su actualización, los espacios virtuales, los materiales de aprendizaje, las herramientas de comunicación y de trabajo colaborativo y las utilidades de gestión educativa.

Entre los más conocidos están:

- Ariadne

- Classnet

- CMU Online

- CourseInfo

- IBT Author

- LearningSpace

- Mentorware

- TopClass

- Toolbook Librarian

- Virtual-U

- WebCT

- Web Course in a Box

- WebMentor

5. Programas para la gestión y la administración académica: Son herramientas que gestionan la matrícula e inscripción de los alumnos en los cursos, proporcionan información académica como horarios, fechas de exámenes, notas, planes de estudios, expedición de certificados, y en algunos casos permiten la gestión docente (elaborar listas, fichas, cartas tipo,...) y tutorial: concretar reuniones, tutorías, etc. 


\section{Lugares donde podemos encontrar información:}

\begin{tabular}{|c|c|}
\hline $\begin{array}{l}\text { Editores de cursos y otros } \\
\text { programas para la creación de } \\
\text { materiales de aprendizaje } \\
\text { multimedia }\end{array}$ & \\
\hline \multicolumn{2}{|l|}{$\begin{array}{l}\text { Composers o editores páginas } \\
\text { web: }\end{array}$} \\
\hline • Page Mill & \\
\hline - Home Page & \\
\hline $\begin{array}{l}\text { - Dreamweaver/Course } \\
\text { Builder }\end{array}$ & \\
\hline \multicolumn{2}{|l|}{ Programas de autor: } \\
\hline $\begin{array}{ll}\text { - Authorware Professional } \\
\text { (Macromedia) }\end{array}$ & \\
\hline $\begin{array}{ll}\text { - } & \text { Quest Net+ (Allen } \\
\text { Communication) }\end{array}$ & \\
\hline $\begin{array}{l}\text { - IconAuthor (Aim Tech } \\
\text { Corp) }\end{array}$ & \\
\hline - Toolbook (Asymetrix) & \\
\hline - Director (Macromedia). & \\
\hline \multicolumn{2}{|l|}{$\begin{array}{l}\text { Programas de creación de } \\
\text { ejercicios: }\end{array}$} \\
\hline - Quizmaker & http://www.quizmaker.com/ \\
\hline - QuestionMark & http://www.questionmark.com/ \\
\hline - Qform, & http://www.satlab.hawaii.edu/space/hawaii/qform.html \\
\hline - QuizCode, & http://www.codeonline.com/products/quizcode.html \\
\hline \multicolumn{2}{|l|}{$\begin{array}{l}\text { Plataformas de trabajo } \\
\text { colaborativo. }\end{array}$} \\
\hline BSCW, & $\begin{array}{l}\text { http://bscw.gmd.de/ } \\
\text { (información sobre uso de BSCW } \\
\text { http://www.rediris.es/cvu/publ/bscw99.html) }\end{array}$ \\
\hline Allaire Forum, & http://www.allaire.com/ \\
\hline Alta Vista Forum, & http://altavista.software.digital.com/forum/ \\
\hline Backtalk, & http://www.wwnet.net/ janc/backtalk/ \\
\hline CaMILE, & http://www.cc.gatech.edu/gvu/edtech/CaMILE.html \\
\hline Caucus, & http://www.caucus.com/ \\
\hline CDboard, & http://www.labgo.com/cdboard/ \\
\hline ClassAct, & http://www.viola-research.com/code/classact \\
\hline ClassPoint, & http://www.wpine.com/products/ClassPoint/index.html \\
\hline$\overline{\mathrm{COSE}}$ & http://web.staffs.ac.uk/COSE/ \\
\hline Centra Symposium, & http://www.centra.com/ \\
\hline FirstClass, & http://www.softarc.com/ \\
\hline$\overline{\text { FORUM, }}$ & http://www.forminc.com/ \\
\hline
\end{tabular}




\begin{tabular}{|c|c|}
\hline iClass, & http://www.sneakerlabs.com/products/iDL/index.html \\
\hline Mayetic Village, & http://es.mayeticvillage.com/home.nsf/Pages/Mayetic \\
\hline LearnLinc, & http://www.ilinc.com/ \\
\hline TOBACO. & http://www.egd.igd.fhg.de/ \\
\hline \multicolumn{2}{|l|}{$\overline{\text { Plataformas de teleformación }}$} \\
\hline - Ariadne & http://ariadne.unil.ch/ \\
\hline - Asymetrix & http://www.asymetrix.com/ \\
\hline - Blackboard & http://www.blackboard.com/ \\
\hline - Classnet & http://classnet.cc.iastate.edu/ \\
\hline - $\quad$ CMU Online & http://online.web.cmu.edu/ \\
\hline - CourseInfo & http://www.courseinfo.com/ \\
\hline - IBT Author & http://www.docent.com/ \\
\hline - LearningSpace & http://www.lotus.com/products/learning \\
\hline - Mentorware & http://www.mentorware.com/ \\
\hline - TopClass & http://www.wbtsystems.com/ \\
\hline - Virtual-U & http://virtual-u.cs.sfu.ca/ \\
\hline - WebCT & http://homebrew.cs.ubc.ca/webct \\
\hline - Web Course in a Box & http://madduck.mmd.vcu.edu/wcb/wcb.html \\
\hline - WebMentor & http://www.avilar.com/ \\
\hline
\end{tabular}

\section{Más información en}

Edu Tools: Información actualizada sobre últimas versiones en http://www.edutools.info/course/productinfo/index.jsp

Incluimos una extensa relación en $\underline{\mathrm{ANEXO} I}$

\section{Sistemas de evaluación y comparativos:}

Edu.Tools http://www.edutools.info/course/compare/index.jsp

Presenta un numeroso grupo de plataformas y un interesante colección de características y utilidades para estudiar.

Elige por el nombre los productos a comparar y muestra en comparación las características y recursos que disponen.

Compara por características. Puede ver una determinada característica o utilidad cómo se presenta en un grupo de plataformas seleccionado.

Puede elegir comparar un grupo de características o bien ampliar el análisis de todos los productos y todas las características.

Marcelo y otros.- ELearning Teleformación. Diseño, Desarrollo y Evaluación de la formación a través de Internet. Editorial Gestión2000. Autores: C. Marcelo, D. Puente, M.A. Ballestero, A. Palazón.

En este libro, de Marcelo y otros, podemos encontrar una interesante revisión de plataformas tecnológicas sobre teleformación.

GATE.- Estudio para la evaluación de plataformas, elaborada por el GATE de la Universidad Politécnica de Madrid . 
Es un completísimo estudio que incluye un extenso número de plataformas. Además es un metarrecurso pues permite acceder a otros sistemas de evaluación y comparativos. http://hermes.gate.upm.es/plataformas/herramientastele/

Universidad de Manitoba.- Tools for Developing Interactive Academic Web Courses http://www.umanitoba.ca/ip/tools/courseware/evalmain.html

Web Based Learning Resources Library .http://www.knowledgeability.biz/weblearning/

EDUTECH.- $\underline{\text { http://www.edutech.ch/edutech/tools/comparison_e.asp }}$

SEAS.- http://www.student.seas.gwu.edu/ tlooms/assess.html

NCSA.- http://www.ncsa.uiuc.edu/ jfile/learnenv/index.html

MARSHALL.- http://www.marshall.edu/it/cit/webct/compare/index.htm

WBTIC.- http://www.webbasedtraining.com/resources_tools.aspx

OUTREACH.- http://www.knowledgeability.biz/weblearning/softwaretools.htm

UIB.- http://mcdce10.uib.es/search.htm

UNED.- http://www.uned.es/catedraunesco-ead/plataformas.htm

THOT.- http://www.thot.cursus.edu/rubrique.asp?no=12074

163 plate-formes de e-formation : le répertoire le plus complet à ce jour...

Conferencing Software for the Web - http://thinkofit.com/webconf/index.htm

A Comparative Analysis of Web-Based Testing and Evaluation Systems http://renoir.csc.ncsu.edu/MRA/Reports/WebBasedTesting.html

Comparison of Online Course Delivery Software Products http://www.marshall.edu/it/cit/webct/compare/index.htm

E-learning: Soluciones de E-learning/ Formación a Distancia - http://elearning.bankhacker.com/

Online educational deliveryapplications - http://www.edutools.info/course/index.jsp 


\section{III}

\section{Unos rasgos para la propuesta de evaluación:}

La última parte de este trabajo está constituida por una extensa y en lo posible detallada reflexión sobre los elementos que deberían fundamentar la inclusión de indicadores en una propuesta de evaluación y de gestión de la calidad en plataformas de teleformación. No es pues en sentido estricto un trabajo exhaustivo ni riguroso que pretenda agotar todos los perfiles del tema y hacerlo con planteamientos o enunciados desprovistos de ambigüedad. Eso es objeto de otro tipo de trabajo. En este caso se pretende exclusivamente llamar la atención, e inducir al debate, sobre una serie de cuestiones que nacen como consecuencia de todo lo anteriormente expuesto. Sin duda el debate servirá para decantar muchas de las cuestiones que se plantean, pulir su perfil conceptual o el de los constructos que encierran, poner de relieve contradicciones, hacer que se manifiesten distintas posturas sobre utilidad, provecho, objetivos, ... en definitiva sobre la fundamentación de la calidad en sistemas de gestión del aprendizaje.

A continuación vamos a centrar pues nuestro trabajo en las dimensiones y los elementos que deben constituir una herramienta de evaluación de un SGA. Consideramos las siguientes categorías:

a. Características básicas.

b. Metadatos

c. Utilidades que generan ambientes de comunicación y de trabajo.

d. Funciones que permite

e. Roles que se identifican

f. Evaluación sobre la intervención psicopedagógica del sistema que soporta.

Pasamos pues a describirlos y a establecer las pautas de análisis.

\section{a. Características básicas}

Ya hemos tratado esta cuestión en el apartado primero de este trabajo. Las características o criterios básicos son las condiciones mínimas que, a nuestro criterio, debe cumplir un SGA para ser considerado como tal. Para ello tenemos en cuenta lo que es común y mayoritariamente aceptado (el mínimo común denominador) en los medios técnicos, lo que se escribe en los artículos y documentos especializados y también en nuestra experiencia. Procede pues del análisis de las herramientas examinadas y utilizadas, del análisis de las funciones y de la configuración tecnológica para realizar esas funciones. Cuando planteamos la exigencia de la publicidad de los principios y objetivos de formación y de intervención formativa, y que estos centren la configuración, estamos de alguna forma poniendo sobre la mesa un modelo de formación transparente y centrado en el usuario, y fundado desde los principios de la planificación curricular y en los principios que rigen los procesos de aprendizaje (psicoeducativos).

De esta forma las características que hemos considerado básicas y sin las cuales un SGA no podría ser considerado como tal (condiciones sine qua non), son:

1. En general corresponde a una descripción o definición de este tipo: Es una herramienta informática y telemática organizada en función de unos objetivos 
formativos que se puedan conseguir exclusivamente a través de ella y de unos principios de intervención psicopedagógica y organizativos claros, explícitos y conocidos por el usuario

2. Posibilita el acceso remoto tanto a profesores como a alumnos en cualquier momento, desde cualquier lugar, mediante conexión a Internet o a redes con protocolo TCP/IP.

3. Utiliza un navegador. Permite a los usuarios acceder a la información a través de navegadores estándares (como Nestscape, Internet Explorer, Opera,..), utilizando el protocolo de comunicación http.

4. El acceso es independiente de la plataforma o del ordenador personal de cada usuario. Es decir utilizan estándares de manera que la información puede ser visualizada y tratada en las mismas condiciones, con las mismas funciones y con el mismo aspecto en cualquier ordenador.

5. Tiene estructura servidor/cliente. Es decir permite a los usuarios retirar y depositar información.

6. El acceso es restringido y selectivo.

7. Incluye como elemento básico una interfaz gráfica común, con un único punto de acceso, de manera que en ella se integran los diferentes elementos multimedia que constituyen los cursos: texto, gráficos, vídeo, sonidos, animaciones, etc.

8. Utiliza páginas elaboradas con un estándar aceptado por el protocolo http: HTML o XML.

9. Realiza la presentación de la información en formato multimedia. Los formatos HTML o XML permiten presentar la información, además de en hipertexto, pueden utilizarse gráficos, animaciones, audio y vídeo (tanto mediante la transferencia de ficheros como en tiempo real).

10. Permite al usuario acceder a recursos y a cualquier información disponible en Internet. Bien a través de enlaces y las herramientas de navegación que le proporciona el navegador en Internet, bien a través del propio entorno de la plataforma.

11. Permite la actualización y la edición de la información con los medios propios que han de ser sencillos o con los medios estándares de que disponga el usuario. Tanto de las páginas web como de los documentos depositados.

12. Tiene estructurada la información y los espacios, en formato hipertextual, de manera que la información esté organizada y estructurada a través de enlaces y asociaciones de tipo conceptual y funcional, de tal forma que queden diferenciados distintos espacios, CON NOMBRES PROPIOS, y que esto sea percibible por los usuarios.

13. Permita establecer diferentes niveles de usuarios con distintos privilegios de acceso.

14. Contempla al menos los siguientes perfiles: el administrador, que se encarga del mantenimiento del servidor, y de administrar espacios, claves y privilegios; el coordinador o responsable de curso, es el perfil del profesor que diseña, y se responsabiliza del desarrollo del curso, de la coordinación docente y organizativa del curso en la plataforma; los profesores tutores, encargados de la atención de los alumnos, de la elaboración de materiales y de la responsabilización docente de las materias; y los alumnos.

\section{b. Metadatos:}


La Metainformación (la metadata o los metadatos, que es indistintamente como se conoce) es la información de referencia sobre un objeto de información, sea éste físico o digital, cuantitativo, cualitativo, o procesual.

La necesidad de la metainformación viene impuesta por el crecimiento exponencial de objetos de información. Pero sobre todo porque, a medida que nuestras necesidades de conocimiento aumentan, de forma más dramática, la falta de información clave o de metainformación nos produce una limitación aún más grave en el uso de esos objetos, de manera que la abundancia de información lleva a un efecto contrario al que parece natural: Nos impide el uso de cualquier información al entorpecer el acceso a ella.

Esto que en general es cierto sucede también con los objetos de aprendizaje en Internet, y en particular con los entornos de gestión del aprendizaje.

Con este fin, para abordar la solución de este problema, la gestión y el uso de objetos de aprendizaje en redes, el grupo de trabajo del IEEE LTSC LOM ${ }^{13}$ ha creado un estándar para la "metainformacion de objetos de aprendizaje" (LOM). Adjuntamos pues el primero de los documentos emanados de este grupo de trabajo que describe el modelo de metainformación estructurado, es el trabajo Learning Object Metadata (LOM) correspondiente al instrumento versión 3, aprobado en 27-11-1999., y que ha sido traducido por Iolanda Rabascall, Miguel Rodriguez Artacho, Jordi Vivancos Martí, con fecha 17/05/00. Otros más recientes se pueden encontrar en http://ltsc.ieee.org/doc/

\section{c. Utilidades de la plataforma que generan ambientes de comunicación y de trabajo.}

Por lo general las plataformas integran herramientas informáticas como el correo electrónico, las listas de correo, los foros, etc que ya funcionaban como servicios de Internet y eran utilizados en la formación a distancia tecnológica (web training). La evaluación de una paltaforma no solo debe identificar estas herramientas sino también algunas caracteristicas técnicas muy significativas como, por ejemplo, si son independientes del entorno y también averiguar si están provistos de ciertas caracteristicas que favorecen los aprendizajes.

En este apartado pues se trata de

a) Identificar primero qué herramientas o utilidades hay o constituyen la plataforma, de forma diferenciada, y que generan ambientes de comunicación y de trabajo.

\footnotetext{
${ }^{13}$ Este documento es un extracto del "Learning Object Metadata. Working Draft Document 3" desarrollado por el grupo de trabajo número 12 del IEEE LTSC (http://ltsc.ieee.org/doc/wg12/LOM-WD3.htm).
}

Traducido por lolanda Rabascall, Miguel Rodriguez Artacho, Jordi Vivancos Martí. 17/05/00

Los capítulos traducidos mantienen la numeración de los apartados del original. 
b) Reconocer, examinar y evaluar distintos aspectos que se consideran interesantes o provechosos desde el punto de vista de la calidad formativa, que facilitan el acceso, la comunicación y el trabajo.

Entre las utilidades distinguimos: Mensajería, listas o grupos de correo, foros asíncronos, foros síncronos - chats, repositorio de documentos, listas de enlaces y bookmarks, editor de documentos y guías didácticas

Y entre los aspectos a evaluar en cada una:

- Facilidad en la identificación. En este apartado se trata de evaluar lo fácilente que el usuario reconoce la herramienta y la distingue del resto de opciones y facilidades. Es decir si se reconoce el servicio fácilmente y su caractere a través de su nombre, identificadores icónicos, ayudas, etc. y las operaciones que permite.

- Facilidad en el acceso y en el funcionamiento. Se trata de evaluar no solo la facilidad con que accedemos habitualmente sino las dificultades que ofrece la configuración y la instalación así como durante su uso.

- Estándar. Se trata de decir en est ecaso si la herramienta responde a algún estandar conocido, por ejemplo mensajería POP-3, videoconferencia RDSI, etc

- Nombre Se trata de decir el nombre que recibe o ifdentificador por el que es reconocido en el contexto de la plataforma

- Distinguen función de edición, de usuario individual, de grupo. Esta característica como la siguiente quedan perfectamente descritas en el enunciado

- Admite privilegios ¿cuáles?

De manera que quedaría una tabla de la forma:

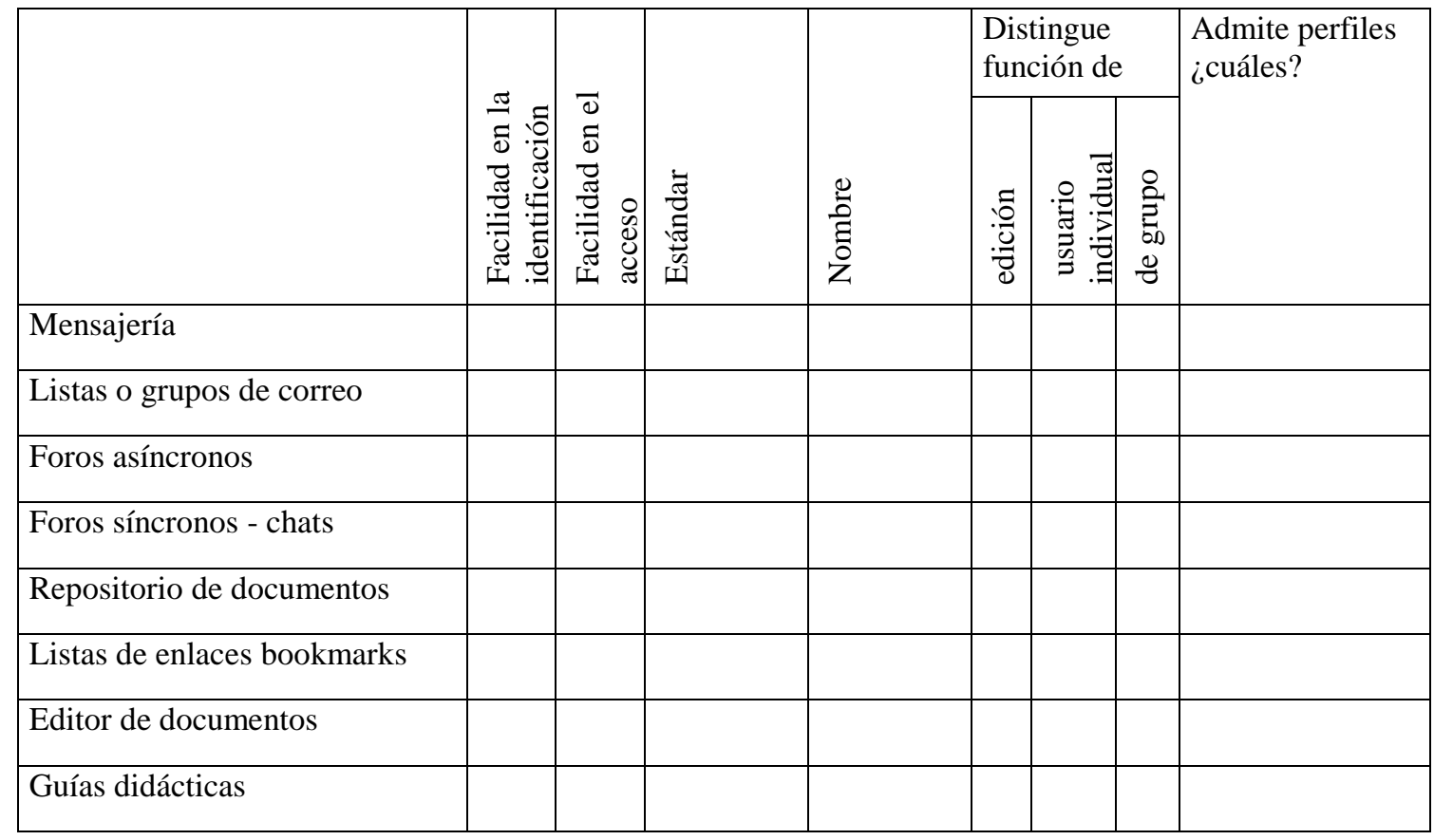




\section{d. Funciones formativas que permite desarrollar el SGA}

Recordemos que nuestro análisis anterior lo centramos en las funciones de tipo formativo que la plataforma permite desarrollar o que se realicen, y entre estas encontramos

\section{Propuesta de itinerario formativo.}

Las preguntas (indicadores) que nos formulamos son, con relación al SGA:

1. Permite establecer distintos itinerarios formativos alternativos

2. El sistema va provisto de itinerarios conformados, así como de criterios de articulación: incompatibilidades, requisitos, orientaciones, pautas, etc.

3. El alumno puede diseñar según sus expectativas e intereses los cursos, materias, seminarios u otras acciones formativas

4. El alumno puede establecer la secuencia de las materias, los cursos u otras acciones formativas.

\section{Propuesta de guía curricular.}

Mediante las guías los tutores, coordinadores, y demás docentes implicados proponen objetivos formativos, establecen el conjunto de actividades y tareas precisas para conseguirlos, los criterios y herramientas de evaluación, así como los procedimientos para evaluar o autoevaluar, también proponen los recursos y la distribución temporal para todo ello.

a. Va provista de editor de guías

b. Hay un lugar en el diseño de cursos para las guías

c. Este lugar ocupa una posición preeminente, visible y de acceso fácil

d. El editor lleva prevista una herramienta que permita establecer enlaces con los materiales que se utilizan en las tareas, recursos en Internet y con otros módulos. (O permite editar HTML)

Apoyo en la formación. Esta función es difícilmente reconocible en la plataforma como tal, está más bien vinculada a la acción docente y a las metodologías de intervención formativa. Nos referimos fundamentalmente a apoyo documental y a recursos formativos: Ejercicios, prácticas, guías didácticas, documentos y textos bases (planos y multimedia), pero también a cualquier otro tipo de apoyo (apoyo multimedia, apoyo experto,...) en recursos como de comunicación, técnicas de estudio y de trabajo intelectual, ayuda de navegación etc.

\section{Seguimiento del progreso del estudiante.}

Nos referimos a todas aquellas opciones y operaciones que proporcionan diferentes tipos de información al profesor, y que le permiten realizar un seguimiento sobre el progreso del alumno. Esta información puede provenir de distintas fuentes, las más de las veces es el tutor quien llevará el registro personalizado del progreso del estudiante mediante métodos convencionales, como es el caso de la relación de ejercicios y tareas propuestas y de los resultados obtenidos, pero otras veces serán instrumentos mecánicos los que permitan realizar ejercicios objetivos pruebas de autoevaluación etc. En cualquier caso podemos plantearnos si la plataforma va provista de 
1. Fichas de anotaciones personalizadas el alumno

2. Test de autoevaluación realizados por los estudiantes

3. Pruebas objetivas con módulo de edición, módulo de ejecución y modulo de corrección.

4. Estadísticas sobre los itinerarios seguidos

5. Estadísticas de los accesos practicados en los materiales de aprendizaje,

6. Estadísticas de la participación de los alumnos a través de herramientas de comunicación (mensajes enviados, participación en debates y calidad de las intervenciones,...), número de veces que ha accedido el alumno al sistema, tiempo invertido, etc.

Todas ellas son viables, es decir actualmente existen dispositivos que las generan automáticamente.

Es pertinente preguntarse igualmente si

- estas herramientas, además de generar estadísticas, generan gráficas sobre cada una de las variables reseñadas.

Comunicación interpersonal. Metodológicamente es el aspecto más importante y definitorio de una plataforma. Esta función constituye uno de los pilares fundamentales dentro de los entornos de aprendizaje en redes, ya que posibilita el intercambio de información, el diálogo y la discusión entre todas las personas implicadas en el proceso y sobre todo las condiciones en que se produce. En función del diseño del curso, y de la plataforma hay distintas formas de integrar aplicaciones de comunicación interpersonal (a veces como herramientas ad hoc, desarrolladas por el propio sistema, y cada vez con más frecuencia por herramientas estándares que el usuario ya utiliza en la vida real, así sucede con el correo POP-3 por ejemplo) como son el correo electrónico, listas, chat, foros, ... Esta aplicaciones se pueden clasificar según el criterio de concurrencia en el tiempo en síncronas (audio/videoconferencia, pizarra electrónica, espacios virtuales, chats...) y asíncronas (correo electrónico, noticias, tablero electrónicos...) o, según el criterio de concurrencia personal, en aplicaciones punto a punto (correo, videoconferencia RDSI,...) o multipunto (listas, chat, videoconferencia VRVS, foros, ...)

La tabla que proponemos de evaluación para este caso es la que sigue.

Herramientas de comunicación interpersonal: 


\begin{tabular}{|c|c|c|c|c|c|c|c|c|c|}
\hline \multirow{3}{*}{\multicolumn{2}{|c|}{$\begin{array}{l}\text { Herramienta de } \\
\text { comunicación } \\
\text { interpersonal que } \\
\text { integra } \\
\end{array}$}} & \multicolumn{3}{|c|}{ Es una herramienta } & \multicolumn{3}{|c|}{$\begin{array}{l}\text { Según la concurrencia } \\
\text { en el tiempo y en la } \\
\text { conexión es una } \\
\text { herramienta } \\
\end{array}$} & \multicolumn{2}{|c|}{$\begin{array}{l}\text { Según la } \\
\text { concurrencia } \\
\text { personal es una } \\
\text { herramienta }\end{array}$} \\
\hline & & \multirow[t]{2}{*}{ Estándar } & \multirow[t]{2}{*}{ Específica } & \multirow{2}{*}{$\begin{array}{l}\text { Ambas } \\
\text { cosas }\end{array}$} & \multicolumn{2}{|c|}{ Asíncrona } & \multirow[t]{2}{*}{ Síncrona } & \multirow{2}{*}{$\begin{array}{l}\text { Punto } \\
\text { a } \\
\text { punto }\end{array}$} & \multirow{2}{*}{$\begin{array}{l}\text { Multi- } \\
\text { punto }\end{array}$} \\
\hline & & & & & $\begin{array}{l}\text { On } \\
\text { line }\end{array}$ & $\begin{array}{l}\text { Of } \\
\text { line }\end{array}$ & & & \\
\hline \multicolumn{2}{|c|}{ Correo } & $\square$ & $\square$ & $\square$ & $\square$ & $\square$ & $\square$ & $\square$ & $\square$ \\
\hline \multicolumn{2}{|c|}{ Correo con attach } & $\square$ & $\square$ & $\square$ & $\square$ & $\square$ & $\square$ & $\square$ & $\square$ \\
\hline \multicolumn{2}{|c|}{ Listas } & $\square$ & $\square$ & $\square$ & $\square$ & $\square$ & $\square$ & $\square$ & $\square$ \\
\hline \multicolumn{2}{|c|}{ Foros } & $\square$ & $\square$ & $\square$ & $\square$ & $\square$ & $\square$ & $\square$ & $\square$ \\
\hline \multicolumn{2}{|c|}{ audioconferencia } & $\square$ & $\square$ & $\square$ & $\square$ & $\square$ & $\square$ & $\square$ & $\square$ \\
\hline \multirow{5}{*}{ 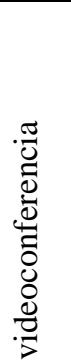 } & $\begin{array}{l}\text { A través de } \\
\text { web }\end{array}$ & $\square$ & $\square$ & $\square$ & $\square$ & $\square$ & $\square$ & $\square$ & $\square$ \\
\hline & M-bonne & $\square$ & $\square$ & $\square$ & $\square$ & $\square$ & $\square$ & $\square$ & $\square$ \\
\hline & RDSI & $\square$ & $\square$ & $\square$ & $\square$ & $\square$ & $\square$ & $\square$ & $\square$ \\
\hline & VRVS & $\square$ & $\square$ & $\square$ & $\square$ & $\square$ & $\square$ & $\square$ & $\square$ \\
\hline & Otra & $\square$ & $\square$ & $\square$ & $\square$ & $\square$ & $\square$ & $\square$ & $\square$ \\
\hline \multicolumn{2}{|c|}{ pizarra electrónica } & $\square$ & $\square$ & $\square$ & $\square$ & $\square$ & $\square$ & $\square$ & $\square$ \\
\hline \multicolumn{2}{|c|}{$\begin{array}{l}\text { espacios virtuales } \\
\text { (decir cuales) }\end{array}$} & $\square$ & $\square$ & $\square$ & $\square$ & $\square$ & $\square$ & $\square$ & $\square$ \\
\hline \multicolumn{2}{|c|}{$\begin{array}{ll}\text { Chat: } & \\
\text { Único } & \square \\
\text { Por materia } & \square \\
\text { Otra distrib. } & \square\end{array}$} & $\square$ & $\square$ & $\square$ & $\square$ & $\square$ & $\square$ & $\square$ & $\square$ \\
\hline \multicolumn{2}{|c|}{ noticias } & $\square$ & $\square$ & $\square$ & $\square$ & $\square$ & $\square$ & $\square$ & $\square$ \\
\hline \multicolumn{2}{|c|}{ tablero electrónico } & $\square$ & $\square$ & $\square$ & $\square$ & $\square$ & $\square$ & $\square$ & $\square$ \\
\hline \multicolumn{2}{|c|}{ Otro: } & $\square$ & $\square$ & $\square$ & $\square$ & $\square$ & $\square$ & $\square$ & $\square$ \\
\hline
\end{tabular}

Trabajo colaborativo. Las plataformas incorporan entornos particulares que permiten el trabajo colaborativo entre los alumnos (o entre profesores). Estos entornos posibilitan compartir información, elaborar, modificar, adicionar,... documentos conjuntos,... mediante facilidades de programación que establecen actualizaciones simultáneas, diferentes versiones,... Esta modalidad de trabajo facilita y entrena para la solución de problemas, la toma de decisiones, el trabajo en grupo, etc.

Además de los entornos de este tipo que integran las plataformas hay herramientas que están pensadas únicamente con este fin. Son las plataformas de trabajo colaborativo. En este caso estos programas llevan opciones específicas orientadas al trabajo cooperativo, como son: transferencia de ficheros (FTPs), aplicaciones compartidas; calendario, chat, convocatoria de reuniones, lluvia de ideas, mapas conceptuales, navegación compartida, notas, pizarra compartida, videoconferencia,... El más conocido de ellos es BSCW.

La plantilla de evaluación debería contemplar pues al menos los siguientes aspectos: 


\begin{tabular}{|c|c|c|}
\hline & SI & $\mathrm{NO}$ \\
\hline 1. Incorpora repositorio de ficheros y documentos & $\square$ & $\square$ \\
\hline 2 Lleva editor individualizado & $\square$ & $\square$ \\
\hline $\begin{array}{l}\text { 3. Permite compartir información, elaborar, modificar, adicionar,... documentos } \\
\text { conjuntos }\end{array}$ & $\square$ & $\square$ \\
\hline $\begin{array}{l}\text { 4. Incorpora facilidades que establezcan actualizaciones simultaneas y diferentes } \\
\text { versiones }\end{array}$ & $\square$ & $\square$ \\
\hline 5 Cree que estas herramientas en este caso permiten y favorecen & $\square$ & $\square$ \\
\hline 5.1 la solución de problemas (las facilita y entrena para ello) & $\square$ & $\square$ \\
\hline 5.2 la toma de decisiones & $\square$ & $\square$ \\
\hline 5.2 el trabajo en grupo & $\square$ & $\square$ \\
\hline $\begin{array}{l}\text { 6. Lleva opciones específicas orientadas al trabajo cooperativo, como son } \\
\text { aplicaciones compartidas. Decir cuales: }\end{array}$ & $\square$ & $\square$ \\
\hline 6.1 & $\square$ & $\square$ \\
\hline 6.2 & $\square$ & $\square$ \\
\hline 6.3 & $\square$ & $\square$ \\
\hline 7. Calendario & $\square$ & $\square$ \\
\hline 8. Convocatoria de reuniones & $\square$ & $\square$ \\
\hline 9. Lluvia de ideas & $\square$ & $\square$ \\
\hline 10. Mapas conceptuales & $\square$ & $\square$ \\
\hline 11. Navegación compartida & $\square$ & $\square$ \\
\hline 12. Notas & $\square$ & $\square$ \\
\hline 13. Pizarra compartida & $\square$ & $\square$ \\
\hline 14. Videoconferencia interna & $\square$ & $\square$ \\
\hline
\end{tabular}

Creación de ejercicios de evaluación y autoevaluación. Como ya hemos señalado otras veces la evaluación de los aprendizajes, no solo en este tipo de entornos, debe ser vista desde dos perspectivas diferentes. Por una parte, la clásica desde el punto de vista del profesor. Ésta le proporcionará informaciones sobre el proceso en la adquisición de conocimientos y destrezas por parte del alumno y también sobre la efectividad del diseño, y sobre el desarrollo, de todo el sistema de formación. La otra perspectiva es la del alumno, la percepción del alumno acerca de su propio progreso se produce a través de ejercicios de autoevaluación. Mediante ellos, o basándose en ellos, recibe 
informaciones y orientaciones sobre el grado y la calidad de los conocimientos adquiridos.

Las plataformas habitualmente van provistas de herramientas que posibilitan diferentes tipos de ejercicios: de respuesta múltiple, de relación, ejercicios cloze, de respuestas booleanas (verdadero/falso, si/no,...), observación visual, etc. y de ejercicios abiertos que puede contrastarse con otros ejercicios de plantilla.

\begin{tabular}{|c|c|c|c|c|}
\hline & 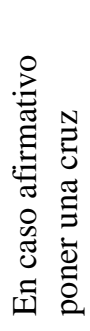 & 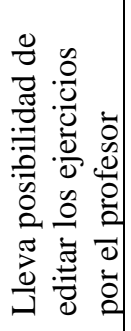 & 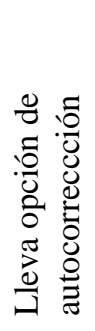 & 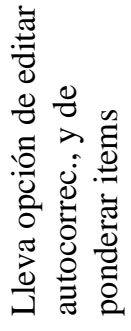 \\
\hline $\begin{array}{l}\text { ¿ Lleva herramientas que posibilitan diferentes tipos de } \\
\text { ejercicios?: }\end{array}$ & [ & 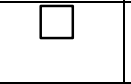 & & L \\
\hline \multicolumn{5}{|l|}{ Si es así señalar las posibilidades que lleva } \\
\hline de respuesta múltiple, & & $\square$ & & $\square$ \\
\hline de relación, & & $\square$ & & $\square$ \\
\hline ejercicios cloze, & $\square$ & $\square$ & & $\square$ \\
\hline de respuestas booleanas (verdadero/falso, si/no,...), & $\square$ & $\square$ & & $\square$ \\
\hline de observación visual & & $\square$ & $\square$ & $\square$ \\
\hline $\begin{array}{l}\text { ejercicios abiertos que puede contrastarse con otros } \\
\text { ejercicios de plantilla. }\end{array}$ & $\square$ & $\square$ & $\square$ & $\square$ \\
\hline Otros: & $\square$ & $\square$ & - & $\square$ \\
\hline
\end{tabular}

Acceso y procesamiento de información y de contenidos de aprendizaje. Las plataformas constituyen parte de eso tan complejo y tan extenso que hemos dado en llamar la sociedad de la información y del conocimiento. Y como tal participa de algunas de las características más importantes de aquella. En este caso se trata de acceder a las ingentes cantidades de información que hay en las redes y a la posibilidad de proceso de esa información obteniendo conocimientos de ella. En particular y específicamente las plataformas proporcionan acceso a recursos singulares de aprendizaje: hipermedias, simulaciones, textos digitales (en diferentes formatos), imágenes, esquemas, ficheros de vídeo o de audio, listas de ejercicios, enunciados y desarrollo de prácticas, tutoriales, glosarios, etc. Además las plataformas mediante guías de recursos y relaciones de enlaces permiten a los alumnos acceder a grandes cantidades de información especializada a través de los múltiples repositorios disponibles en Internet como: bases de datos on-line o bibliográficas; sistemas de información y buscadores temáticos; libros digitales, informaciones en vídeo, audio, videoclips; publicaciones electrónicas; centros de interés (bibliotecas y museos digitales,...), enciclopedias, diccionarios, traductores, $\ldots$

\begin{tabular}{|l|c|c|}
\hline & SI & NO \\
\hline Lleva acceso a enlaces de internet & $\square$ & $\square$ \\
\hline
\end{tabular}




\begin{tabular}{|l|c|c|}
\hline $\begin{array}{l}\text { Lleva acceso a enlaces de Internet personalizados } \\
\text { (Bookmarks o favoritos) }\end{array}$ & $\square$ & $\square$ \\
\hline Permite editar enlaces y categorías & $\square$ & $\square$ \\
\hline Lleva categorización de enlaces por materias & $\square$ & $\square$ \\
\hline Lleva otro tipo de categorización estándar & $\square$ & $\square$ \\
\hline
\end{tabular}

Interacción. La comunicación interpersonal es estéril si no va acompañada de la capacidad de modificar e intervenir en los procesos cognitivos y en cambio de actitudes de los otros y los otros en las nuestras. Es decir sin interacción.

En los entornos de enseñanza basados en la web podemos diferenciar al menos cuatro niveles de interacción entre: profesor-alumno, alumno-alumno, alumno-contenidos de aprendizaje y profesor-profesor. A diferencia de como sucede en otras funciones, no hay herramientas asociadas a esta función: Se produce o no se produce, en todas y en cada una, aunque va vinculada especialmente a algunas: Correo, listas,... No obstante un elemento de calidad es la posibilidad que presentan algunas plataformas de tener diferentes utilidades vinculadas a herramientas como es el portafolio, el correo electrónico vinculado con la gestión de alumnos y los resultados de los ejercicios de evaluación, de forma que el profesor puede enviar mensajes individuales a los alumnos en función de las respuestas y el procedimiento de resolución o del resultado de un ejercicio propuesto.

\begin{tabular}{|l|c|c|}
\hline & SI & NO \\
\hline $\begin{array}{l}\text { Permite visualizar al usuario, sea profesor o alumno, quien está conectado en cada } \\
\text { momento (profesor alumno) }\end{array}$ & $\square$ & $\square$ \\
\hline $\begin{array}{l}\text { Permite visualizar quien está conectado en cada momento, pero con limitaciones: solo } \\
\text { a los profesores, solo permite detectar qué alumnos están conectados,... }\end{array}$ & $\square$ & $\square$ \\
\hline $\begin{array}{l}\text { Tiene portafolio vinculado al resto de herramientas de forma que se pueda congregar } \\
\text { toda la información de un alumno procedente del correo, las listas, los repositorios de } \\
\text { documentos, etc. }\end{array}$ & $\square$ & $\square$ \\
\hline $\begin{array}{l}\text { Tiene recursos automatizados vinculados con la gestión docente personalizada. Por } \\
\text { ejemplo enviar mensajes tipo a alumnos que no hayan presentado la tarea e un plazo, } \\
\text { u otros similares. }\end{array}$ & $\square$ & $\square$ \\
\hline
\end{tabular}

Gestión y administración educativa de los alumnos. No consideramos aquí los entornos de gestión administrativa de la formación a través de redes, que permiten llevar a cabo todas aquellas actividades relacionadas con la gestión académica de los alumnos como son matriculación, consulta del expediente académico y de las calificaciones, expedición de certificados,... que constituyen capítulo aparte, que deberían tener en cuenta criterios y requisitos procedentes del análisis de los objetivos formativos, y que frecuentemente no solo se lo saltan sino que los afectan.

En este punto de lo que hablamos es de las funciones, de organización y gestión de los alumnos y de los grupos, que tienen que ver en cómo se organiza la enseñanza, el aprendizaje, los recursos y la evaluación.

Por ejemplo hablamos de la elaboración de grupos, de horarios, de calendarios, pero sobre todo de funciones que afectan nuclearmente a la gestión del proceso de enseñanza-aprendizaje, como son establecer privilegios de acceso, con la importancia que tiene en la creación modificación de roles y perfiles docentes, la creación de grupos, 
el acceso a la información sobre alumnos, la creación de listas y plantillas para seguir y evaluar el progreso en el aprendizaje, la elaboración, diseño y gestión de espacios, etc.

\begin{tabular}{|c|c|c|}
\hline & SI & NO \\
\hline $\begin{array}{l}\text { Dispone de un interface practicable por el coordinador o equivalente que permite } \\
\text { conceder y retirar privilegios al resto de usuarios según perfiles y funciones atribuidas, } \\
\text { modificando los perfiles docentes y discentes }\end{array}$ & & \\
\hline $\begin{array}{l}\text { Dispone de un interface practicable por el tutor dando acceso a los alumnos a los espacios } \\
\text { docentes y altas/bajas y otras funciones determinadas en la programación }\end{array}$ & & \\
\hline $\begin{array}{l}\text { Dispone de un interface practicable por el administrador de las listas y los foros regulando } \\
\text { la participación en los debates (concediendo y retirando privilegios de participación: } \\
\text { Todos, solo lectura, lectura y escritura moderada, etc.). }\end{array}$ & & \\
\hline Permite la creación de grupos, en general o de alguna forma & & \\
\hline $\begin{array}{l}\text { A todos los profesores sobre los alumnos que tiene responsabilidad en la materia } \\
\text { que es titular }\end{array}$ & & \\
\hline Solo al administrados y al coordinador & & \\
\hline A cualquier profesor & & \\
\hline Permite el acceso a la información sobre alumnos, fichas de alumnos & & $\square$ \\
\hline $\begin{array}{l}\text { Permite la creación de listas y plantillas para seguir y evaluar el progreso en el } \\
\text { aprendizaje }\end{array}$ & & \\
\hline $\begin{array}{l}\text { Permite (bien al coordinador, o a los tutores) la elaboración, diseño y gestión de espacios } \\
\text { virtuales distintos del curso: Unidades, lecciones, temas, capítulos, epígrafes,... } \\
\text { estableciendo enlaces y accesos con el resto de elementos (herramientas y recursos) que } \\
\text { se utilizan en cada unidad }\end{array}$ & & 4 \\
\hline
\end{tabular}

\section{Utilidades vinculadas a funciones.}

Independientemente de este análisis es también pertinente plantearse en modo particular cómo resuelve cada plataforma la realización de algunas de las funciones señaladas, de forma que en una evaluación sistemática tengamos la oportunidad de conocer a qué herramientas opciones o utilidades están más vinculadas: 


\begin{tabular}{|c|c|c|c|c|c|c|}
\hline & & A través de...(i) & $\begin{array}{l}\text { Indepen- } \\
\text { dencia } \\
\text { (ii) }\end{array}$ & $\begin{array}{l}\text { Facilidad } \\
\text { para } \\
\text { identificar } \\
\text { (iii) }\end{array}$ & $\begin{array}{l}\text { Facilidad } \\
\text { de acceso } \\
\text { (iii) }\end{array}$ & $\begin{array}{l}\text { Facilidad } \\
\text { de uso (iii) }\end{array}$ \\
\hline \multirow{4}{*}{ 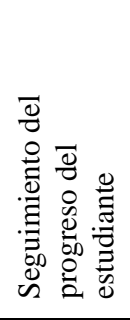 } & Portafolio & & & & & \\
\hline & Pruebas objetivas & & & & & \\
\hline & Análisis de tarea & & & & & \\
\hline & \begin{tabular}{|l|} 
Análisis de \\
intervenciones en \\
debates
\end{tabular} & & & & & \\
\hline \multirow{3}{*}{ 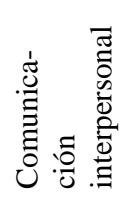 } & Prof/alumno & & & & & \\
\hline & Alumno/ alumno & & & & & \\
\hline & Prof/Prof & & & & & \\
\hline \multirow{5}{*}{ 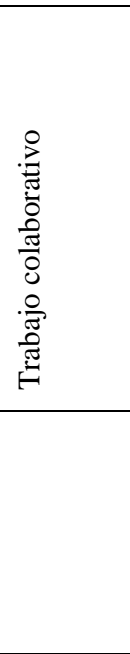 } & \begin{tabular}{|l|} 
Compartir \\
información
\end{tabular} & & & & & \\
\hline & $\begin{array}{l}\text { Elaborar, } \\
\text { modificar, } \\
\text { adicionar,... } \\
\text { documentos } \\
\text { conjuntos } \\
\end{array}$ & & & & & \\
\hline & $\begin{array}{l}\text { Facilita y entrena } \\
\text { para la solución } \\
\text { de problemas }\end{array}$ & & & & & \\
\hline & $\begin{array}{l}\text { Facilita y entrena } \\
\text { para la toma de } \\
\text { decisiones }\end{array}$ & & & & & \\
\hline & $\begin{array}{l}\text { Facilita y entrena } \\
\text { para la el trabajo } \\
\text { en grupo. }\end{array}$ & & & & & \\
\hline
\end{tabular}

(i) Se pide que se diga a qué o a cuáles herramientas va vinculada esta función. La posibilidad de "evaluación mediante portaforlio", por ejemplo, puede ir vinculada a una utilidad con ese nombre, o bien a una carpeta, sistema de carpetas, directorios,....

(ii) Se pide que se diga en qué porcentaje es una opción metodologías y en que tanto por ciento va vinculada a la opción en cuestión. Por ejemplo el análisis de la tarea va muy poco o nulamente asociado a una opción o utilidad de la plataforma, es una función casi exclusivamente de trabajo del profesor, no está mediatizada apenas por el ordenador. El porcentaje de independencia será muy alto $100 \%$ o $90 \%$

(iii) Estas opciones se formalizarán solo en el caso de que el porcentaje anterior no sea $100 \%$. Es decir cuando la función vaya vinculada en alguna medida a una opción de programa. En ese caso puntuar de 1 a 5, correspondiendo 5 al grado mayor: Máxima facilidad de acceso, máxima facilidad de uso, etc. 


\section{d. Roles que se identifican}

En el artículo de RED 1 Formación abierta y a distancia a través de redes digitales: Modelos de redes de aprendizaje ${ }^{14}$ establecíamos los rasgos de algunos perfiles participantes en los SGA, y decíamos:

\section{El alumno}

El estudiante, alumno, aprendiz, discente,...., o como indistintamente se le llame, queda definido claramente por su situación de aprendizaje y es el centro de todos los procesos y el sujeto de los aprendizajes y de la acción formativa (es el que aprende y a quien se enseña). En el esquema que estamos trabajando interactúa en el entorno de Campus Virtual con el resto de elementos de la siguiente forma:

Con el tutor de aprendizaje, consultor, etc a través de la tutoría telemática. o eventualmente a través de consultas por otros medios presenciales, teléfono, videoconferencia,...

Con el tutor personal a través de consultas por las distintas vías

Interactúa grupalmente con otros alumnos y con profesores a través de los foros, entendidos tanto como espacios como metodología.

Interactúa con otros alumnos grupal o individualmente a través de los distintos canales de comunicación de tipo académico o de relación social, lúdica, etc.

El perfil pedagógico dentro del esquema del Campus Virtual y el perfil de comunicación y de relación del alumno viene determinado por su situación de aprendizaje y de expectativas intereses, etc. recordemos que el estudiante virtual es por lo general un individuo entre 25 y 50 años con un perfil profesional activo.

\section{Los profesores.-}

Los Campus Virtual habitualmente están adscritos a alguna universidad o consorcio de universidades, de esta forma el cuerpo docente está formado por profesores de la entidad matriz especialistas en las materias titulares y por lo general con una buena disposición y motivados hacia esta modalidad de enseñanza. Como veremos es esencial el papel que juegan los equipos docentes. Igualmente es frecuente encontrar colaboradores procedentes del mundo profesional que se nuclean en torno a estos equipos. Igualmente es habitual encontrar colaboradores locales vinculados a centros asociados o centros de apoyo.

\section{Tutores personales.-}

En tanto que tutores no son estrictamente docentes. Son profesores asignados a cada alumno y que tienen como función facilitar la vida escolar de estos, sus relaciones con la institución y con el resto de profesores, coordinadores, etc. En los Campus Virtual es fácil detectar la situación de soledad, frustración y abandono se trata de evitar estas situaciones y sensaciones con un apoyo efectivo.

También tiene funciones

Orientadora, es asesor académico personal, debe conocer la carrera y las opciones elegidas por el alumno así como su situación en relación con los objetivos personales, académicos, expectativas,... y de aumentar o mantener el

\footnotetext{
${ }^{14}$ Miguel Zapata, 2002 Formación abierta y a distancia a través de redes digitales: Modelos de redes de aprendizaje RED, num. 1 pag 6 a 9. www.um.es/ead/red/
} 
interés y la motivación por los estudios. Debe establecer contactos periódicos y regulares.

De mediación entre ellos y la institución en los procedimientos administrativos, entre ellos y los otros profesores, detectando posibles deficiencias, problemas en el aprendizaje en los materiales, etc.

\section{Tutores de aprendizaje, consultores, mentores,....-}

Cada materia tiene su propio tutor que es el que se responsabiliza del aprendizaje del alumno en esa materia y en sus bloques de contenidos. Su acción se lleva a cabo a través de la elaboración de la guía, él solo o en grupo, la propuesta de actividades, la supervisión de la ejecución de las tareas asignadas a los alumnos (supervisión de forma individual dotándose de instrumentos de seguimiento en la ejecución de las tareas y de evaluación de los resultados obtenidos), la participación en los foros y debates,... Igualmente realiza la tutoría telemática atendiendo las consultas de los alumnos a través de correo electrónico, propone los ejercicios y realiza la corrección de estos, proponiendo actividades de mejora, ampliación,...

Además ejercen una labor grupal de dinamización del aprendizaje, son los moderadores de los foros, organizan las guías y las intervenciones.

El tutor debe colaborar con el profesor encargado del espacio virtual a la hora de organizar los servicios y recursos que componen el espacio de la materia, de modo que el resultado esté en correspondencia con el diseño de las guías y del plan docente. Vigilando que los tiempos y los recursos se adecuen a lo establecido en la guía didáctica de la materia y también que la estructura hipertextual y de espacios se correspondan con la estructura lógica y funcional de la guía didáctica y del plan docente. Los espacios habituales son los originados por y para el almacenamiento de la mensajería, el tablero del profesor, las bases de datos de las listas de distribución y los FTP, así como los espacios web de las guías.

En el supuesto óptimo el tutor de materia o de aprendizaje debe responsabilizarse de la elaboración, ejecución y evaluación del plan docente de la materia. Esto supone que con anterioridad a la ejecución del curso o al menos antes de que comience su materia el tutor debe haber elaborado y coordinado con el resto de los componentes del curso (tutores, encargados del espacio virtual,...) con la colaboración del coordinador. El plan docente debe contener al menos:

La guía del bloque de contenidos o de la materia, que ya hemos comentado que incluye las pautas y los tiempos para que los alumnos progresen en la consecución de los objetivos de la materia. Muy importante debe ser la claridad con que se describen las tareas a realizar y los tiempos asignados, esta información es imprescindible que sea conocida por los alumnos y que esté en un lugar de la web muy accesible y con enlaces a los elementos que desde allí se citan.

Procedimiento para evaluar los conocimientos y habilidades previos, y en su caso una propuesta para conseguir un grado de homogeneización que posibilite el desarrollo de la materia.

Criterios por los que se han seleccionado esos contenidos de manera que complementen y se coordinen con los restantes (esto no es distinto de lo que sucede en otras modalidades de enseñanza, pero en este caso adquiere especial relevancia) y criterios por los cuales se secuencian los contenidos de la forma 
en que se proponen.

Distribución temporal.

Metodología que se propone para cada actividad, con especial indicación de los recursos a utilizar en ese caso y la forma de su uso. Algunos campus contemplan este apartado de forma muy elaborada constituyendo un elemento altamente significativo dentro de su modelo pedagógico, configurándolo incluso como una opción docente del campus electrónico.

Criterios de evaluación de los aprendizajes, tanto durante la realización de las actividades (evaluación formativa) como de evaluación final.

El titular del plan docente es la materia, no el profesor, de manera que si hay varios tutores que imparten una misma materia deben elaborar y seguir un mismo plan docente. Esto implica un especial compromiso de trabajo en grupo que los docentes han de tener en cuenta cuando optan por esta modalidad.

El tutor de aprendizaje debe colaborar estrechamente con el colaborador presencial a la hora de diseñar los instrumentos de evaluación formativa y de evaluación final.

Cada alumno tiene tantos tutores de aprendizaje como materias curse.

\section{Colaboradores en entornos presenciales (centros de apoyo, centros asociados,....)}

Como sucede con el resto de figuras docentes el profesor colaborador local pueden corresponder a un perfil docente definido o a una función ejercida por otros profesores. De esta manera el tutor de aprendizaje cuando se desplaza a un centro de apoyo, para ayudar a los alumnos, se está convirtiendo en un colaborador local. En general el profesor de apoyo o colaborador local tiene como misión completar la acción formativa o evaluativa de forma presencial.

\section{Especialistas en elaboración de material didáctico}

Tres rasgos definen a este tipo de docente: Experto en contenidos propios de la materia que se imparte, conocedor del lenguaje hipermedia y multimedia y sobre todo conocedor de las metodologías de educación a distancia y en la repercusión que este hecho tiene para la elaboración de este tipo de materiales: Que sean autoinstructivos, autoevaluativos, adaptados a las situaciones de aprendizaje y al perfil del aprendiz... y que reúnan el resto de características que en su momento comentamos.

\section{Gestión de los espacios virtuales}

La tarea de gestionar los espacios virtuales, de estudiar y establecer los criterios de acceso, de organizar el propio acceso a través de enlaces en la web, de organizar las bibliotecas virtuales y los tiempos, la secuencia y el periodo de permanencia en la red de los materiales, son tareas eminentemente docente, en función de que sus características se derivan de unos criterios de selección y de secuenciación de los contenidos y de los objetivos de formación, de un conocimiento de los perfiles personales y cognitivos de los alumnos y de la necesidad de coordinar las actividades y los recursos que se utilizan en ellas.

Por otra parte la gestión técnica eficaz por parte de los gestores de las redes demanda que los equipos docentes hablen con una sola voz y con criterios claros de organización. 


\section{Coordinador}

El coordinador o jefe de estudios, según otras denominaciones, supone en la mayor parte de los campus virtuales la garantía de que el equipo docente funcione como tal. En esto no hay diferencia con cualquier otra organización educativa en cualquier modalidad de enseñanza. Su singularidad en este caso proviene de que el ámbito de actividad común de los profesores es mucho mayor: Comparten espacios, recursos y tiempos no solo en todo el campus virtual en su conjunto, en los espacios virtuales, en cada programa de formación o en cada curso, sino incluso dentro de cada materia o bloque de contenidos. De esta forma mientras en la enseñanza presencial en cada asignatura intervienen un profesor que es responsable de la programación de aula y de su ejecución, en esta modalidad de formación intervienen los distintos tipos de profesores que hemos visto: El tutor de aprendizaje, el encargado de recursos, el colaborador local, los que elaboran los materiales,... Esta mayor complejidad se manifiesta también a la hora de elaborar y coordinar los distintos planes docentes.

Por otra parte cuando habábamos de requisitos básicos para una plataforma decíamos:

Contempla al menos los siguientes perfiles: el administrador, que se encarga del mantenimiento del servidor, y de administrar espacios, claves y privilegios; el coordinador o responsable de curso, es el perfil del profesor que diseña, y se responsabiliza del desarrollo del curso, de la coordinación docente y organizativa del curso en la plataforma; los profesores tutores, encargados de la atención de los alumnos, de la elaboración de materiales y de la responsabilización docente de las materias; y los alumnos.

El instrumento de evaluación ha de verificar por tanto si existen al menos estos perfiles, y posiblemente otros. Y sobre todo ha de contemplar cual es la política de privilegios, a qué espacios y herramientas tiene acceso cada uno y con qué modalidad de uso, así como la política de edición de documentos y los atributos de cliente/servidor en los servicios de repositorio de documentos: ¿Quién deposita y quién retira documentos y materiales y con qué criterios?

\begin{tabular}{|l|c|c|}
\hline Perfiles que contempla de forma explícita & SI & NO \\
\hline Alumno & $\square$ & $\square$ \\
\hline Tutor personal & $\square$ & $\square$ \\
\hline Tutor de aprendizaje & $\square$ & $\square$ \\
\hline Profesor responsable o titular de materia & $\square$ & $\square$ \\
\hline Coordinador & $\square$ & $\square$ \\
\hline Administrador & $\square$ & $\square$ \\
\hline Especialista en elaboración de material educativo multimedia & $\square$ & $\square$ \\
\hline Colaborador remoto, en sedes locales & $\square$ & $\square$ \\
\hline Evaluador u observador externo & $\square$ & $\square$ \\
\hline Otros perfiles docentes & & \\
\hline & $\square$ & $\square$ \\
\hline & $\square$ & $\square$ \\
\hline Otros perfiles no docentes & & \\
\hline & $\square$ & $\square$ \\
\hline & $\square$ & $\square$ \\
\hline
\end{tabular}


Deberíamos pues plantearnos, a raíz de lo visto, el análisis de los perfiles participantes y la plataforma al menos bajo tres puntos de vista: Términos, relaciones y privilegios:

\section{Términos.-}

Las palabras o descriptores de un perfil deben ser precisos, únicos y sin ambigüedades en todos los puntos de la plataforma donde se citen. Y deben corresponder a la misma conceptualización.

Los descriptores de un perfil son precisos, únicos y sin ambigüedades en todos los puntos de la plataforma donde se citan. Y corresponden a la misma conceptualización

Relaciones.- Debe permitir de forma fácil y fluida, esto es con opciones visibles de forma inmediata.

El alumno cuando acceda a su curso, desde su perspectiva, o explícitamente desde su página personal debe percibir al menos las opciones y facilidades siguientes: Situación en que se encuentra en el contexto del curso (Unidad, tareas pendientes, tareas propuestas, y enlace con comunicaciones recientes no vistas), tutores, acceso a material, a herramientas de comunicación interpersonal o grupal.

Igualmente debe suceder al profesor con relación a los alumnos y materias que le son asignados o que tutela. Pero además con facilidades de edición. 


\begin{tabular}{|c|c|c|c|}
\hline Perfiles & Informaciones y acceso desde la situación inicial & SI & NO \\
\hline \multirow[t]{5}{*}{ Alumno } & $\begin{array}{l}\text { Informaciones en relación con la situación en que se encuentra en el contexto } \\
\text { del curso (Unidad, tareas pendientes, tareas propuestas, y enlace con } \\
\text { comunicaciones recientes no vistas). }\end{array}$ & $\square$ & $\square$ \\
\hline & Acceso a tutores & $\square$ & \\
\hline & Acceso a material, & $\square$ & \\
\hline & Acceso a herramientas de comunicación interpersonal o grupal. & $\square$ & \\
\hline & & $\square$ & \\
\hline \multirow[t]{5}{*}{ Tutor personal } & $\begin{array}{l}\text { Todas las informaciones y posibilidades de acceso que disponen los } \\
\text { participantes tutelados }\end{array}$ & $\square$ & \\
\hline & Acceso a las bases de datos de alumnos & $\square$ & \\
\hline & & $\square$ & \\
\hline & & $\square$ & \\
\hline & & $\square$ & \\
\hline \multirow[t]{6}{*}{ Tutor de aprendizaje } & $\begin{array}{l}\text { Todas las informaciones y posibilidades de acceso que disponen los } \\
\text { participantes tutelados }\end{array}$ & $\square$ & \\
\hline & Acceder a la información de los alumnos asignados & $\square$ & \\
\hline & $\begin{array}{l}\text { Acceso a las herramientas de gestión del aprendizaje de forma diferenciada: } \\
\text { Editores de ejercicios, pruebas de evaluación, guías de aprendizaje, fichas de } \\
\text { los alumnos, portafolios,... }\end{array}$ & $\square$ & 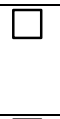 \\
\hline & & $\square$ & \\
\hline & & $\square$ & \\
\hline & & $\square$ & \\
\hline \multirow[t]{6}{*}{$\begin{array}{l}\text { Profesor responsable o } \\
\text { titular de materia }\end{array}$} & \begin{tabular}{|l}
$\begin{array}{l}\text { Todas las informaciones y posibilidades de acceso que disponen los } \\
\text { participantes asignados }\end{array}$ \\
\end{tabular} & $\square$ & \\
\hline & Acceder a la información de los alumnos (como cliente) & $\square$ & \\
\hline & $\begin{array}{l}\text { Acceso a las herramientas de gestión de los recursos y guías didácticas de la } \\
\text { materia, de forma diferenciada: Editores, guías didácticas,... }\end{array}$ & $\square$ & \\
\hline & & $\square$ & \\
\hline & & $\square$ & \\
\hline & & $\square$ & \\
\hline \multirow[t]{4}{*}{ Coordinador } & $\begin{array}{l}\text { Acceso al interface de coordinador, donde están las herramientas que le } \\
\text { permiten ejercer sus privilegios y funciones }\end{array}$ & $\square$ & L \\
\hline & & $\square$ & \\
\hline & & $\square$ & \\
\hline & & $\square$ & \\
\hline \multirow[t]{4}{*}{ Administrador } & $\begin{array}{l}\text { Acceso al interface de administrador, donde están las herramientas que le } \\
\text { permiten ejercer sus privilegios y funciones }\end{array}$ & $\square$ & $\square$ \\
\hline & & $\square$ & \\
\hline & & $\square$ & \\
\hline & & $\square$ & \\
\hline \multirow{3}{*}{$\begin{array}{l}\text { Especialista en } \\
\text { elaboración de material } \\
\text { educativo multimedia }\end{array}$} & Acceso a un interface propio para colocar materiales de prueba & $\square$ & \\
\hline & $\begin{array}{l}\begin{array}{l}\text { Todas las informaciones y posibilidades de acceso que disponen los } \\
\text { participantes. }\end{array} \\
\end{array}$ & $\square$ & \\
\hline & & $\square$ & $\square$ \\
\hline \multirow[t]{4}{*}{$\begin{array}{l}\text { Colaborador remoto, en } \\
\text { sedes locales }\end{array}$} & \begin{tabular}{|l}
$\begin{array}{l}\text { Todas las informaciones y posibilidades de acceso que disponen los } \\
\text { participantes tutelados }\end{array}$ \\
\end{tabular} & $\square$ & $\square$ \\
\hline & Acceder a la información de los alumnos asignados & $\square$ & $\square$ \\
\hline & & $\square$ & $\square$ \\
\hline & & $\square$ & $\square$ \\
\hline \multirow{2}{*}{$\begin{array}{l}\text { Evaluador u observador } \\
\text { externo }\end{array}$} & & $\square$ & $\square$ \\
\hline & & $\square$ & $\square$ \\
\hline
\end{tabular}




\section{Privilegios.-}

El perfil del alumno como los demás quedan caracterizados, en relación con la plataforma, por la capacidad de modificación que tiene del entorno operativo o de las informaciones que contiene.

De esta manera el alumno debe como mínimo tener la capacidad de disponer de un espacio cliente al que pueda acceder depositando materiales y modificando su estructura, el árbol de carpetas y directorios de ahí para abajo. 


\begin{tabular}{|c|c|c|c|}
\hline Perfiles & Privilegios & SI & NO \\
\hline \multirow[t]{3}{*}{ Alumno } & $\begin{array}{l}\text { Disponer de un espacio cliente al que pueda acceder } \\
\text { depositando materiales y modificando su estructura, el árbol de } \\
\text { carpetas y directorios de ahí para abajo. }\end{array}$ & $\square$ & $\square$ \\
\hline & & $\square$ & $\square$ \\
\hline & & $\square$ & $\square$ \\
\hline \multirow[t]{5}{*}{ Tutor personal } & $\begin{array}{l}\text { Disponer de un espacio cliente al que pueda acceder } \\
\text { depositando materiales y modificando su estructura, el árbol de } \\
\text { carpetas y directorios de ahí para abajo. }\end{array}$ & $\square$ & $\square$ \\
\hline & Acceder a información de los alumnos asignados & $\square$ & $\square$ \\
\hline & Editar fichas de alumnos & $\square$ & ह \\
\hline & & $\square$ & $\square$ \\
\hline & & $\square$ & $\square$ \\
\hline \multirow[t]{5}{*}{ Tutor de aprendizaje } & $\begin{array}{l}\text { Disponer de un espacio cliente al que pueda acceder } \\
\text { depositando materiales y modificando su estructura, el árbol de } \\
\text { carpetas y directorios de ahí para abajo. }\end{array}$ & $\square$ & $\square$ \\
\hline & Acceder a información de los alumnos asignados & $\square$ & $\square$ \\
\hline & \begin{tabular}{|l|} 
Editar fichas de alumnos \\
\end{tabular} & $\square$ & \\
\hline & Acceder a espacio de los alumnos como cliente/servidor & $\square$ & \\
\hline & Dar altas y bajas de alumnos & $\bar{\square}$ & \\
\hline \multirow{5}{*}{$\begin{array}{l}\text { Profesor responsable o titular } \\
\text { de materia }\end{array}$} & Dispone de los privilegios propios de un tutor de aprendizaje & 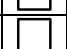 & \\
\hline & Acceso cliente único al repositorio de materiales de la materia. & $\square$ & \\
\hline & Administrar recursos de la materia, foros, listas,... & $\square$ & \\
\hline & & $\square$ & \\
\hline & & $1 \square$ & \\
\hline Coordinador & Acceso cliente único a las guías didácticas & $\square$ & 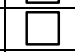 \\
\hline & & $\square$ & \\
\hline & & $\square$ & L \\
\hline \multirow{3}{*}{ Administrador } & Conceder retirar privilegios & 남 & t \\
\hline & Diseño de espacios & $\square$ & 는 \\
\hline & Asignar espacios & $\square$ & L \\
\hline & & $\square$ & \\
\hline \multirow[t]{2}{*}{$\begin{array}{l}\text { Especialista en elaboración de } \\
\text { material educativo multimedia }\end{array}$} & $\begin{array}{l}\text { Disponer de un espacio cliente al que pueda acceder } \\
\text { depositando materiales y modificando su estructura, el árbol de } \\
\text { carpetas y directorios de ahí para abajo. }\end{array}$ & $\square$ & $\square$ \\
\hline & & $\square$ & $\square$ \\
\hline \multirow[t]{4}{*}{$\begin{array}{l}\text { Colaborador remoto, en sedes } \\
\text { locales }\end{array}$} & $\begin{array}{l}\text { Disponer de un espacio cliente al que pueda acceder } \\
\text { depositando materiales y modificando su estructura, el árbol de } \\
\text { carpetas y directorios de ahí para abajo. }\end{array}$ & $\square$ & $\square$ \\
\hline & Acceder a información de los alumnos asignados & $\square$ & $\square$ \\
\hline & Editar fichas de alumnos & $\square$ & $\square$ \\
\hline & & $\square$ & \\
\hline $\begin{array}{l}\text { Evaluador u observador } \\
\text { externo }\end{array}$ & & $\square$ & $\square$ \\
\hline
\end{tabular}




\section{e. Evaluación sobre la intervención psicopedagógica del sistema que soporta.}

A este respecto debemos tener en cuenta lo que se dice en el mismo artículo citado ${ }^{15}$, en la segunda parte, donde se dan las claves para construir algunos indicadores, de tipo psicopedagógico y de diseño curricular, en relación con el modelo de EAD que se quiere propiciar. Además se proponen una serie concreta de indicadores que razonablemente se debieran incluir en un instrumento de evaluación de la calidad debidamente adaptado y formulado:

Aunque todos los sistemas de enseñanza a distancia basados en tecnología digital utilizan con mayores o menores diferencias los mismos servicios de las redes ---que son los que por otra parte la tecnología ofrece en cada instante---, existe una gran diversidad en las propuestas en el mercado de la teleformación. Lo que caracteriza a un sistema no son las herramientas que se usan. Lo que varía de un sistema a otro, en relación con la dimensión puramente formativa, su eficiencia pedagógica, etc., no es pues en esencia el recurso que utiliza, sino el papel que cumplen los personajes implicados (profesores, tutores, mentores, organizadores,...), así como la propia organización de los elementos materiales y la organización de la información. Son éstos elementos que encierran un valor intrínseco superior al de los recursos, que no es más que un valor potencial. Este hecho plantea de entrada una necesidad: la de contar con instrumentos que permitan diferenciar los sistemas de teleformación a partir de elementos definitorios de cada una de las dimensiones que constituyen el sistema de formación: organización, recursos, individuos, informaciones, ... y vincular rasgos de calidad, de eficiencia pedagógica con ellos.

En una primera aproximación al problema se nos plantea la necesidad de diferenciar los elementos que definen un modelo, los principios de intervención psicopedagógica que inspiran el sistema, o más bien en qué rasgos se plasman esos principios. $Y$ en una segunda fase aparece la necesidad de definir indicadores que nos digan en qué grado están acentuados estos rasgos y vincular esos elementos con criterios de calidad.

De esta forma, en un principio, el objetivo será identificar aquellos elementos que permiten definir un modelo de EAD, tanto a partir de los recursos y servicios --considerando los rasgos propios y de uso, que estos presentan (lo que constituyen los entornos tecnológicos)---, como de identificar los rasgos que adquieren los personajes implicados.

De esta manera la intensidad, o la mayor o menor acentuación, que aquellos presentan se traduce en variables susceptibles de caracterizar distintos tipos de entornos de enseñanza y aprendizaje (así hablamos de entornos y modelos más o menos abiertos, más o menos participativos, etc). De igual forma los conjuntos de características de los personajes constituyen perfiles específicos.

De modo que los tres elementos ---recursos, metodologías y perfiles--interrelacionados constituyen entornos complejos que varían según las estrategias de inserción y de relación que se definan entre ellos.

Otra referencia igualmente decisiva es la ubicación, de cada uno de los elementos dentro del sistema que constituyen las informaciones, las características de estas, el flujo de su circulación y los nodos.

\footnotetext{
${ }^{15}$ Miguel Zapata, 2002 Formación abierta y a distancia a través de redes digitales: Modelos de redes de aprendizaje RED, num. 1 pag 6 a 9. www.um.es/ead/red/
} 
A través de este análisis, y de un ejercicio de síntesis, llegamos a la conclusión de que varios son los parámetros o variables que en resumen definen un modelo de EAD: En qué medida es o se puede definir como más o menos abierto, interactivo, integrador, participativo, innovador y transparente.

\section{Abierto:}

En general el carácter abierto de un sistema tiene que ver con la posibilidad de, o su mayor facilidad para, adaptarse a situaciones distintas y cambiantes permitiendo la intervención de los usuarios desde distintas situaciones personales, profesionales o tecnológicas. Este carácter se puede definir bajo distintas perspectivas: Teniendo en cuenta las posibilidades que debe ofrecer el currículo para integrar a alumnos con distintas situaciones iniciales, o bien que se produzcan de forma sobrevenida, y también desde el punto de vista de las posibilidades que ofrecen los medios tecnológicos utilizados y su organización para permitir el acceso al ususario/alumno desde distintas situaciones tecnológicas, o desde distintas plataformas informáticas (estándares de ordenadores y redes, sistemas operativos,...) , o desde distintas concepciones del mundo informático, terminologías, etc.

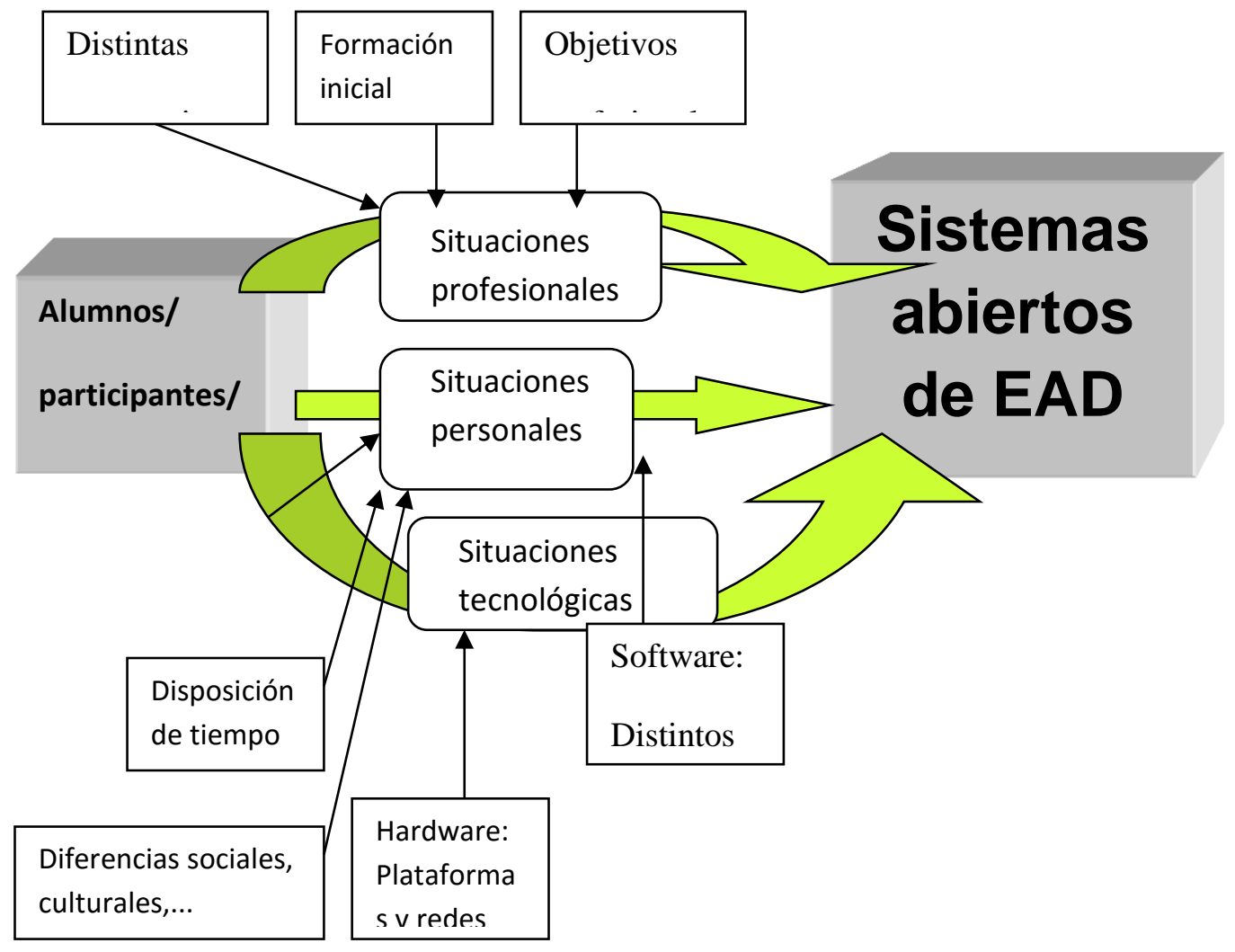

En este sentido el concepto de abierto tecnológicamente tiene mucho que ver con el concepto de software abierto (o de multimedia abierto) que se utilizaba con relación a los programas educativos de ordenador en la época del CAI-EAO (computer asisted instruction - enseñanza asistida por ordenador). Por otra parte el carácter abierto de un entorno de EAD, o de su correlato tecnológico, tiene que ver pues con la capacidad que, en una situación de EAD, debe caracterizar al sistema para ayudar en situaciones distintas de todo tipo, bien de forma inicial o sobrevenida a lo largo del proceso 
formativo. Recordemos que no en balde la EAD (enseñanza ABIERTA y a distancia) supone la alternativa para situaciones de este tipo ---aislamiento, exclusión,...--- no solamente promovidas por obstáculos debido a la distancia.

Pero un sistema no es solo abierto porque permita el acceso y la operatividad a usuarios-alumnos provenientes de distintas situaciones personales o profesionales o tecnológicas, previas o sobrevenidas, sino porque además lo hace con relación a profesores y a sistemas tecnológicos:

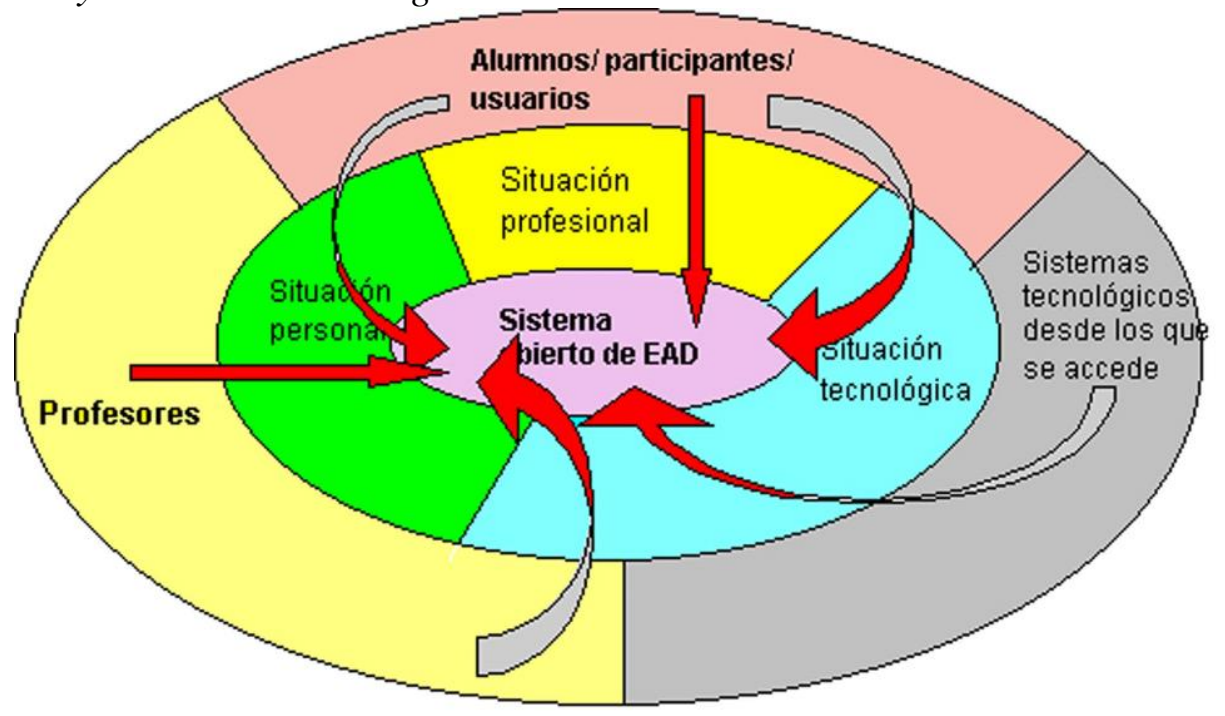

De esta forma en el esquema se simboliza, en la elipse más externa, los principales participantes o componentes (en el caso de las redes) del sistema EAD, que acceden en el transcurso de las actividades al sistema. Son los alumnos, participantes o usuarios -- en el caso más general son profesionales en servicio o en expectativa de serlo en un plazo más o menos prolongado----, los profesores, entendido el concepto en el sentido más amplio: tutores, mentores, coordinador,... y en tercer lugar los sistemas tecnológicos desde donde en modo cliente acceden, los que participan en el sistema o pueden participar en un futuro, o en la actualidad de forma potencial. En este último apartado incluimos los sistemas remotos de los alumnos, sus servidores de correo de Internet de videoconferencia, los equipos personales, los servidores corporativos que los hospedan, las redes nacionales,... el software de comunicaciones o de usuario que utilizan,... Obviamente también incluimos los ordenadores y redes de los docentes, organizadores y técnicos del propio sistema de EAD.

En la elipse del centro simbolizamos el propio sistema de EAD, y en la intermedia las características de las modalidades de acceso de los componentes, agrupadas en tres grandes bloques que constituyen a grandes rasgos las situaciones que se pueden producir: la situación personal, la situación profesional y la situación tecnológica.

La situación personal está caracterizada por una ubicación geográfica con unas características propias de accesibilidad, horarios, tarifas de comunicación,.... , la situación específica de disposición de tiempo, movilidad, etc. También está caracterizada por unas dimensiones culturales, uso del idioma, hábitos sociales, por una disponibilidad económica,... 
La situación profesional o académica también condiciona el acceso de los alumnos/usuarios sobre todo si pensamos en los usuarios que son profesionales en activo desde la perspectiva de la formación de postgrado o de profesionales en potencia si pensamos en las titulaciones de grado universitario o de formación profesional. En este sentido debemos pensar en cuestiones tales como las distintas expectativas que se plantean en el desempeño de su profesión o al iniciar los estudios a distancia, la formación inicial, el ámbito profesional de donde proceden, y los objetivos profesionales (es decir lo que pretenden con la formación).

Por último la situación tecnológica está definida por características de los equipos, las redes y los programas con que acceden al sistema físico que soporta el sistema de formación.

Como vemos en el diagrama de las elipses, la situación tecnológica afecta a la forma de acceso de alumnos, profesores y de los elementos tecnológicos. La situación personal afecta a alumnos y profesores y entendemos que la situación profesional esta intimamente ligada al desarrollo del proceso formativo en los alumnos.

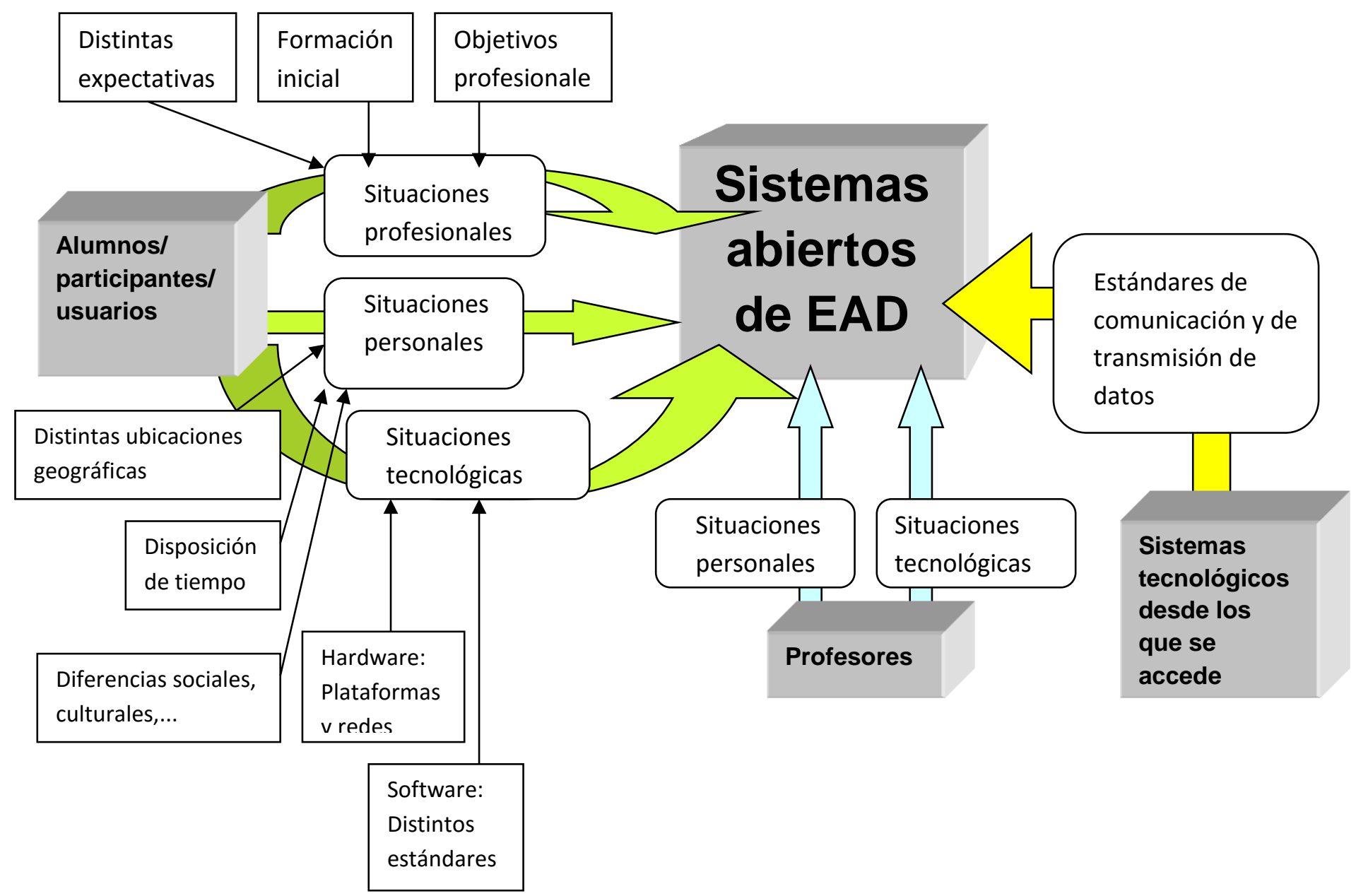

Evidentemente un modelo será tanto más abierto cuanto mayor sean las posibilidades de acceso y de adaptación del sistema a estas situaciones.

El carácter abierto de un sistema puede tener dos sentidos según se aplique a los recursos o a los métodos y procedimientos para la formación: 


\section{Tecnológicamente abierto}

Para que un sistema de EAD sea tecnológicamente abierto deben de concurrir una serie de requisitos en su sistema físico, tanto en la configuración de redes y de ordenadores como en los servicios y en las posibilidades de acceso, de manera que esta configuración palie o atenúe al máximo las dificultades. Tanto las derivadas de la situación tecnológica de acceso, como de situaciones que no son producidas por la situación tecnológica de acceso sino como consecuencia de una inadecuada configuración del sistema o de una mala práctica, o frecuentemente ---desde nuestra perspectiva--- derivada de unos principios de planificación inadecuados. En este sentido cabe decir que, aunque todos los criterios y principios de planificación curricular son igualmente respetables y las razones que los justifican tiene una lógica sin duda consistente con los objetivos que persiguen los organizadores, por lo que respecta a nosotros creemos que el carácter de tecnológicamente abierto de un entorno de teleformación se deriva y es consecuente con el principio de transparencia tecnológica. Según este principio (en una de sus consecuencias) si el medio tecnológico no es transparente, o en la medida que no lo sea, se añaden aprendizajes adicionales a los que suponen los contenidos específicos del programa de formación en el que estemos trabajando.

Pero el carácter tecnológicamente abierto de un sistema de EAD no solo debe paliar las dificultades o problemas derivados de la situación tecnológica de acceso, sino las que se deriven de la situación personal o profesional, independientemente de que sea tecnológicamente viable el que se eludan estas dificultades o se atenúen. De esta forma por ejemplo la posibilidad de una comunicación asíncrona facilitará la resolución de problemas derivados de una disposición irregular de tiempo o la existencia individuos implicados en la formación con distintos horarios.

Nuestra experiencia basada en circunstancias de este tipo nos lleva a la consideración de que un sistema tecnológico de EAD al menos debe de cumplir los siguientes requisitos:

- debe ser asincrónico o albergar al menos la posibilidad de trabajo asíncrono

- debe albergar estándares de comunicación y proceso. Los estándares de videoconferencia H.320 permiten la comunicación a través de varios tipos de redes de comunicación RDSI-ISDN, ADSL, ... y de diversos estándares de sistemas de video. Además el estándar H.323 permite comunicar con ordenadores personales dotados de webcam y Netmeeting.

- debe posibilitar el acceso a través de mensajería POP 3, ello permite dos cosas:

- trabajar desconectado de la red (off line). De esta manera, sin el apremio de que corra la cuenta de teléfono o de ocupar la línea, se fomenta una mayor reflexión en el trabajo. Se puede leer en un momento, escribir la respuesta o realizar la tarea en otro, buscar informaciones adicionales, investigar, pensar, mejorar el estilo y por último emitir una respuesta más elaborada.

- utilizar el programa de mensajería con el que el usuario, alumno o profesor, estén habituados a trabajar. 
En cualquier caso, y en un plano más propiamente tecnológico, un sistema de formación no se podría considerar abierto si no permitiese la integración de nuevos elementos en distintos niveles: a redes más amplias y a otras redes corporativas de interés común o convergente, y a nuevos estándares de hardware y software en presencia o por venir.

\section{Pedagógicamente abierto:}

La planificación curricular y la práctica del curso deben hacerse contemplando la multiplicidad de situaciones que pueden producirse como consecuencia de la variedad de formas de acceso y de las circunstancias profesionales, personales y tecnológicas en las que pueden estar insertos los alumnos, los profesores o incluso el entorno tecnológico de ordenadores y redes. En este caso la intervención personal debe suplir posibles déficits o limitaciones de los recursos tecnológicos. Debe permitir y favorecer la intervención de los individuos implicados posibilitando incluso la adecuación del entorno y de sus componentes estructurales, curriculares, etc. a nuevas situaciones o posibilidades.

Un currículo abierto debe contemplar la posibilidad de incluir en la programación adaptaciones a situaciones especiales, con actividades, evaluaciones, etc. alternativos. También debe contemplar la posibilidad de tratamientos singulares para alumnos con circunstancias extraordinarias sobrevenidas a lo largo del curso.

\section{Interactivo:}

Como hemos visto, hay una serie de problemas y de situaciones que son barreras para el aprendizaje: El medio geográfico ---difícil acceso, aislamiento, lejanía...---, disposición irregular de tiempo, determinadas condiciones sociales, humanas, profesionales,... ---pensemos en ciertas profesiones, en población hospitalizada, reclusa,... ---- y por supuesto ciertas discapacidades

De forma tradicional la educación a distancia ha supuesto un cierto grado de resolución de estos problemas, o de respuesta a estas situaciones, con dos elementos que han sido consustanciales: Una cierta liberación de las condicionantes de espaciotiempo y la ruptura del esquema enseñanza-aprendizaje. Sin embargo la EaD convencional (o tradicional, no tecnológica, la que utilizaba el correo postal y el teléfono o las emisiones de radiodifusión y TV, aunque fuese por satélite) era una formación diferida, con una respuesta muy lejana, en el tiempo, de cuando se producía la necesidad, o con una respuesta escasa, insuficiente o nula. Donde el poder evocador se había perdido. Incluso la respuesta al ser general perdía su capacidad de motivación que tienen las respuestas personalizadas e inmediatas. En definitiva se trataba de una respuesta con bajo potencial interactivo. Muchos de esos rasgos se conservan en algunos modelos actuales de sistemas de EaD. Sin embargo con la presencia del correo electrónico, los attachs, el FTP, las listas de distribución, la videoconferencia RDSI,... aumentan los elementos de diálogo, autonomía, de autorregulación y reflexión. En definitiva aumentan las oportunidades para que la educación a distancia tecnológica se convierta en interactiva.

Estos cambios, si son aprovechados, afectan a profesores, alumnos y recursos.

Los profesores en la EAD cambian su rol, pasan de impartir conocimientos en el aula a ser mediadores y dinamizadores de la actividad educativa, trabajan en equipo y producen recursos (documentos, guías, materiales de apoyo) que sirven de soporte a los contenidos, a las actividades, a la evaluación, que deben contener referencias $e$ 
indicadores del progreso dl aprendizaje y que en todo caso le debe permitir tomar decisiones sobre la orientación de su acción... Aumentan su capacidad de intervención $y$ de cambio en función de las necesidades que detectan y de las señales que perciben. Si la formación se basa en redes la acción del profesor se caracteriza además porque ve aumentado su capacidad de organizar los recursos (establece espacios, redes, enlaces,...).

Los recursos de la EaD en general deben integrar elementos que permitan el autoaprendizaje (que los hagan más autoinstructivos) y la autoevaluación. Deben integrar elementos que permitan al alumno percibir su progreso en el aprendizaje y efectuar eventualmente cambios o correcciones.

En los alumnos de la educación a distancia (convencional o tecnológica) se potencian aspectos tales como: La autonomía general, el autoaprendizaje y la autoformación, la autorregulación y la autoevaluación... Si la formación es tecnológica aumentan también los factores de interacción y de trabajo en equipo. Aparece un nuevo concepto y un entorno de relación: la comunidad virtual.

En definitiva un sistema será tanto más interactivo cuanto más posibilite el diálogo de los individuos entre sí ---de los alumnos con los profesores, de los alumnos con los alumnos, de los profesores con los alumnos y entre ellos,...--- o con el sistema de manera que cada intervención encuentre una respuesta en función de su naturaleza, y que esta sea diferenciada e inmediata.

Indicadores que identifican la interactividad de un sistema serían pues

1. Con relación al uso de las herramientas tecnológicas:

1.1 Tiempo, número y frecuencia de las respuestas

- ¿Qué tiempo como máximo tiene un mensaje en ser respondido por un tutor, o en obtener respuesta desde el sistema?

- Esto también es aplicable a una consulta a través de cualquier medio, o a la corrección de un trabajo o de un ejercicio.

- ¿Qué número de alumnos y por consecuencia de mensajes e intervenciones atiende un tutor de forma simultánea?

- ¿Con qué frecuencia intervienen los alumnos con sus preguntas o con sus intervenciones en los foros $u$ otras formas de participación?

1.2 ¿Se utilizan modalidades de uso interactivo de los servicios de las redes?

- ¿Se potencian los foros, listas de discusión etc. para emitir mensajes encadenados y con carácter de debate con un hilo conductor, respuestas, contrarrespuestas, etc. o simplemente para exponer trabajos, opiniones, etc.?

- ¿Hay posibilidad de seguir el hilo de un debate o de rastrear las intervenciones desencadenadas por, o a propósito de, un tema mediante bases de datos de intervenciones?

- ¿Se utiliza la videoconferencia de forma eminentemente expositiva o se utiliza para trabajo en grupo (telegrupo)?

- Los cuestionarios en la web (form) ¿se utilizan?, ¿para qué?, ¿se procesa la información? ¿cuál es el proceso? ¿se devuelve? ¿con qué tiempo? 
2. Con relación a la planificación y a las distintas componentes curriculares:

2.1 Actividades:

Tiene que ver bastante con lo tratado en el apartado anterior y se refiere a la posibilidad de tener respuesta, el número, frecuencia y el tiempo de respuesta con relación a las actividades:

- ¿Se recepcionan las actividades con un mensaje de acuse de recibo o con algún otro método?

- ¿Qué tiempo como máximo tiene una actividad (o una consulta a través de cualquier medio, o a la corrección de un trabajo o de un ejercicio) en obtener un informe una nota evaluativa de un tutor, o en general en obtener respuesta desde el sistema?.

- ¿Hay segundas réplicas o segundas correcciones? ¿o el proceso se detiene en la primera lectura y valoración?

- ¿Qué número de alumnos y por consecuencia de mensajes e intervenciones atiende un tutor de forma simultánea?

- ¿Con qué frecuencia intervienen los alumnos con sus preguntas o con sus intervenciones en los foros $u$ otras formas de participación?.

2.2 Metodología, objetivos de formación, recursos y evaluación:

La interactividad en la evaluación permite detectar de forma matizada y diferenciada, con referencia a un momento concreto, la consecución o el grado de progresión en los objetivos de formación, o la eficacia de las metodologías utilizadas o el adecuado uso de los recursos. De esta forma a partir de instrumentos específicos de evaluación de aprendizajes, a partir del análisis de las tareas y de las actividades podemos detectar la progresión personal en la consecución de los objetivos de aprendizaje. También con la ayuda de formularios y con el análisis de documentos y de mensajes, intervenciones o pidiéndolo explícitamente podemos obtener datos sobre la marcha de las actividades: grado de satisfacción, consecución de los objetivos personales con relación al curso, clima de grupo, y otras referencias que constituyen las informaciones a analizar en los procesos de evaluación formativa y de proceso:

2.2.1 Evaluación de aprendizajes

¿Se devuelve el análisis de las tareas y de las actividades realizadas? ¿con qué frecuencia?

2.2.2 Evaluación de proceso y evaluación formativa:

¿Existen de una forma metódica instrumentos para recabar la opinión de los estudiantes respecto de

Se utiliza para ello

$$
\begin{aligned}
& \text { metodología y estrategias docentes } \\
& \text { recursos } \\
& \text { clima grupal }
\end{aligned}
$$

$$
\begin{array}{ll}
\text { \# la mensajería } \\
\text { \# formularios de respuestas abiertas } \\
\text { \# formularios de respuesta múltiple }
\end{array}
$$

2.2.3 respecto de la situación personal:

¿Existen de una forma metódica instrumentos para recabar la opinión 

¿Existen procedimientos o está previsto el análisis y la detección de situaciones personales previas al abandono?
¿Están suficientemente caracterizadas estas situaciones de forma que se puedan prevenir?

\section{Integrador.}

Un sistema de EAD es tanto más integrador en la medida en que se propicien espacios de comunicación y de desarrollo entre los individuos en distintas situaciones de aprendizaje, de enseñanza y de relación.

La integración ha de producirse al menos a tres niveles: Integración docente, integración de alumnos o de participantes, entre ellos y con el resto de individuos implicados, e integración de recursos.

\section{Integración docente:}

La integración docente se produce sobre la base de la acción planificadora y evaluadora. A través de reuniones y actividades de coordinación docente, de la realización de planes de trabajo y de programaciones, de su ejecución y de su evaluación formativa.

¿Existen reuniones de coordinación entre los tutores y los demás docentes?

¿Con qué frecuencia?

¿Existen planes de trabajo docente individualizados por materia o por profesor?

\section{Plan docente de la materia y guías didácticas.}

Cada materia tiene su propio tutor que es el que se responsabiliza del aprendizaje del alumno en esa materia y en sus bloques de contenidos. Su acción se lleva a cabo a través de la elaboración de la guía didáctica y está orientada a través de su plan docente. La elaboración de ambos la hace el tutor, solo o en grupo coordinado con el resto de tutores de esa materia. Contiene la propuesta de actividades, la supervisión de la ejecución de las tareas asignadas a los alumnos (supervisión de forma individual dotándose de instrumentos de seguimiento en la ejecución de las tareas y de evaluación de los resultados obtenidos), la participación en los foros y debates,... Igualmente incluye, si hay lugar, las pautas de la tutoría telemática en relación con las consultas de los alumnos a través de correo electrónico, los ejercicios y la corrección de estos, así como sobre las actividades de mejora, ampliación,...

El tutor debe colaborar con el profesor encargado del espacio virtual a la hora de organizar los servicios y recursos que componen el espacio de la materia.

Toda esta información y la justificación correspondiente constituye el plan docente de la materia, junto con las guías didácticas. 
Por tanto debe haber una coordinación entre los docentes implicados, de modo que el resultado esté en correspondencia con el diseño de las guías y del plan docente.

En el supuesto óptimo el tutor de materia o de aprendizaje debe responsabilizarse de la elaboración, ejecución y evaluación del plan docente de la materia. Esto supone que con anterioridad a la ejecución del curso o al menos antes de que comience su materia el tutor debe haber elaborado y coordinado con el resto de los componentes del curso (tutores, encargados del espacio virtual, ...) con la colaboración del coordinador.

La guía del bloque de contenidos o de la materia, que ya hemos comentado incluye las pautas y los tiempos para que los alumnos progresen en la consecución de los objetivos de la materia. Muy importante debe ser la claridad con que se describen las tareas a realizar y los tiempos asignados, esta información es imprescindible que sea conocida por los alumnos y que esté en un lugar de la web muy accesible y con enlaces a los elementos que desde alli se citan.

El titular del plan docente es la materia, no el profesor. De manera que si hay varios tutores que imparten una misma materia, una buena integración docente se produce si todos siguen un mismo plan docente. Esto implica un especial compromiso de trabajo en grupo que los docentes han de tener en cuenta cuando optan por esta modalidad. Además el tutor de aprendizaje debe colaborar estrechamente con el colaborador presencial a la hora de diseñar los instrumentos de evaluación formativa y de evaluación final.

¿Existe guía didáctica para cada bloque o materia?

¿Se ha elaborado de forma coordinada?

¿Es conocida de forma previa por los alumnos?

El plan docente debe contener al menos:

- La guía didáctica del bloque de contenidos o de la materia.

- Procedimientos para evaluar los conocimientos y habilidades previos, y en su caso una propuesta para conseguir un grado de homogeneización que posibilite el desarrollo de la materia.

- Criterios por los que se han seleccionado esos contenidos de manera que complementen y se coordinen con los restantes (esto no es distinto de lo que sucede en otras modalidades de enseñanza, pero en este caso adquiere especial relevancia) y criterios por los cuales se secuencian los contenidos de la forma en que se proponen.

- Distribución temporal.

- Metodología que se propone para cada actividad, con especial indicación de los recursos a utilizar en ese caso y la forma de su uso. Algunos campus contemplan este apartado de forma muy elaborada constituyendo un elemento altamente significativo dentro de su modelo pedagógico, configurándolo incluso como una opción docente del campus electrónico.

Criterios de evaluación de los aprendizajes, tanto durante la realización de las actividades (evaluación formativa) como de evaluación final. 
Integración de alumnos: En todos los sentidos, como veremos, pero sobre todo tendiendo a propiciar la constitución de una comunidad virtual, para ello es especialmente importante la configuración de los recursos.

La existencia de una comunidad virtual es especialmente importante como favorecedora de los aprendizajes, como elemento creador de motivaciones y de estímulos no estrictamente académicos pero con honda repercusión en el entorno académico.

La comunidad virtual está constituida por el conjunto de relaciones que se producen entre los participantes y espacios de relación donde se desarrollan, entre los que se incluyen los no estrictamente académicos.

La comunidad virtual está constituida por los elementos de relación interpersonal entre los profesores y alumnos y que se manifiesta en las actividades de la tutoría como son la orientación y el apoyo personal y en el aprendizaje pero también a la hora de resolver dudas proponer tareas personales, a la hora de recibir las sugerencias y propuestas de los tutores, etc. Pero sobre todo, y de forma singular, a la hora de participar en la vida escolar, o haciendo que esta vida escolar exista como valor añadido a la vida académica. Para ello es especialmente importante que existan espacios abiertos donde los participantes se sientan libres para comunicarse por medio de foros, páginas reservadas a estos temas, actividades lúdicas,...

En este sentido se debe cuidar que la organización del sistema de EAD reserve un espacio al foro. Este es el espacio común, no estrictamente curricular, compartido por el tutor (como un participante más, sin función preeminente de ningún tipo) y por todos los alumnos. En él se tratan todos los temas grupales que no tiene que ver estrictamente con el desarrollo de los contenidos. Además es donde se expresan opiniones sobre la materia, la marcha del curso, los materiales, u otras actividades profesionales, lúdicas, personales o de interés común para todos o para algún grupo. Es un espacio más abierto que el espacio de debate. Se puede articular sobre una lista, o en algunos casos sobre un chat, ICQ,.... Puede también cumplir el papel del tablero del profesor de manera que en él se comuniquen convocatorias, etc. En cualquier caso es el espacio donde se cobra conciencia de comunidad virtual, o de comunidad de grupo de clase virtual.

Para fomentar la comunidad virtual es especialmente importante que los tutores, el coordinador y los colaboradores locales no solo cobren conciencia sobre este tema sino que incluyan entre sus actividades y en sus programaciones actuaciones específicas orientadas a impulsar la comunidad virtual: Reuniones presenciales grupales cuando no se puedan hacer plenarias, espacios en las videoconferencias, moderación de los foros, etc.

\section{Integración de los recursos:}

Es importante estudiar y planificar la estructura de los espacios y servicios en la red que integren el sistema con criterios de utilidad y de favorecer la fácil circulación de los usuarios por ellos, de manera que se consiga finalmente un todo integrado. De esta forma adquiere especial importancia el diseño de los enlaces en la web, y acordar antes criterios del tipo "lo más importante más accesible". También es importante que la 
estructura de los enlaces refleje la estructura funcional de las informaciones en el curso, estudiar las relaciones de los componentes que constituyen el sistema en la red: web, acceso a archivos de listas, FTP, y organizarlo con estos criterios. Y por último integrar aquellos recursos que estén en la red y completen las informaciones propias del curso o sean útiles a los objetivos planteados.

Pero, siendo esto último importante, lo realmente diferenciador de un modelo de EAD es tener en cuenta qué elemento o conjunto de elementos son los que determinan en última instancia la organización de los recursos. De esta forma podemos hablar de sistemas centrados en los medios, cuando es la naturaleza de éstos la que determina su organización, de sistemas centrados en los contenidos, de sistemas centrados en el profesor,.. Si bien un sistema debe integrar los distintos elementos, bajo nuestra perspectiva constructivista, el alumno se sitúa en el centro de todo el proceso. De esta forma podemos hablar de sistemas centrados en el alumno.

Este es un punto de vista ya clásico, vigente en buen parte de nuestra cultura del aprendizaje, que hace especial énfasis en la idea del alumno como centro de los procesos cognitivos y por ende de los procesos de enseñanza y de aprendizaje, y que sitúa los recursos en un esquema complejo de contenidos, procesos y condiciones de aprendizaje.

Desde la perspectiva del constructivismo pues, en toda situación de aprendizaje hay presentes tres elementos, o grupos de elementos claramente diferenciados (Zapata, 1999): Los resultados del aprendizaje o contenidos (QUÉ se aprende), los procesos (CÓMO se aprende) y las condiciones de aprendizaje (lo que ha de cumplir una actividad o una situación para que el aprendizaje se produzca). En esta línea de pensamiento los contenidos serían el resultado del aprendizaje, es decir el cambio que se produce en el material cognitivo del alumno entre el antes y el después de la actividad de aprendizaje. Los procesos serían el CÓMO se aprende, es decir la actividad cognitiva que el aprendiz pone en marcha, para efectuar el aprendizaje (y que dependen en buena medida de sus estrategias y de su estilo cognitivo) y que varían según el tipo de aprendizaje, según la naturaleza del contenido ---hechos, conceptos,... o dominio disciplinar--- y según la información previa (ideas previas, experiencias). Pero en cualquier caso (Pozo, 1987) estos procesos tienen una característica común: son procesos propios, internos e inherentes al aprendiz, y en consecuencia sólo observables en sus efectos. En consecuencia la intervención del profesor para propiciar el cambio en el material cognitivo del que hemos hablado (del cambio conceptual), o dicho de otra forma los procesos de enseñanza, sólo puede intervenir para crear condiciones favorables a ese cambio. O para que el proceso de aprendizaje se desencadene, y se desarrolle, dentro de unas condiciones favorables. Cada aprendizaje requiere unas condiciones concretas y diferentes a otro. Condiciones a determinar mediante procesos de planificación y de evaluación. Estas condiciones de aprendizaje están determinadas por dos elementos: LOS RECURSOS EDUCATIVOS y las estrategias de enseñanza, y por la interacción de ambos. Es en este marco de referencia en el que entendemos el uso de los medios tecnológicos y las redes, como recursos educativos singulares que favorecen aprendizajes asociados a situaciones especificas y en relación con estrategias didácticas propias, y que en conjunto configuran entornos tecnológicos de aprendizaje.

Por tanto debe haber una coordinación entre los docentes implicados, de modo que el 
resultado esté en correspondencia con el diseño de las guías y del plan docente. Vigilando que los tiempos y los recursos se adecuen a lo establecido en la guía didáctica de la materia y también que la estructura hipertextual y de espacios se correspondan con la estructura lógica y funcional de la guía didáctica y del plan docente. Los espacios habituales son los originados por y para el almacenamiento de la mensajería, el tablero del profesor, las bases de datos de las listas de distribución y los FTP, así como los espacios web de las guías.

El alumno es pues el sujeto, el objetivo y el autor de su propio aprendizaje y por tanto el sistema debe ser un sistema centrado en el aprendiz de forma que los recursos estén pensados, en su organización y en su uso, de forma que satisfagan los objetivos primordiales en este sentido: Máxima flexibilidad para el alumno y que posibilite el apoyo personalizado, dentro de esta perspectiva constructivista, donde el alumno sea y se sienta como protagonista de su propio aprendizaje. Sin entrar demasiada profundidad en los principios del constructivismo y del aprendizaje significativo, si que podemos decir que una estructura flexible de los recursos sí que posibilita una mayor autonomía, un mejor autoconcepto (sensu contrario los sistemas y programas que se enganchan, se cuelgan o solo admiten una forma de operar conllevan una mayor sensación de inseguridad personal), aumentan los elementos de motivación, interés,... y por añadidura posibilitan que el alumno sea autónomo, pueda aprender a su estilo, pueda atribuir significado a los conceptos en relación con sus experiencias y conceptos previos sin interferencias del medio. En definitiva se pueda sentir protagonista de su proceso de aprendizaje.

El sistema de apoyo al aprendizaje virtual está constituido por el conglomerado de individuos, situaciones, actividades y relaciones que forman de manera integrada la estructura de intervención y de asistencia en los procesos de aprendizaje y enseñanza propiamente dichos. Es decir todo lo que en el campus virtual no son ordenadores y redes y apoyan a que se produzcan los procesos de enseñanza y de aprendizaje.

En última instancia el éxito o el fracaso del carácter integrador de un sistema de EAD viene determinado, desde esta perspectiva constructivista, por la configuración del sistema de apoyo al aprendizaje. Desde este punto de vista el sistema debe al menos responder a lo siguientes criterios y debe de tener las siguientes características:

1. Se deben precisar de forma clara los objetivos de formación (expresados en capacidades) que el participante debe alcanzar y los contenidos que debe adquirir. Así como los criterios de evaluación parejos a ellos.

2. Igualmente se debe planificar la secuencia de actividades, el ritmo y la distribución temporal necesarios. Las pautas deben ser, claras, públicas y flexibles.

3. La conceptualización asumida del profesor como orientador y supervisor del proceso. Es quien da las pautas, propone las informaciones y las actividades, facilita los recursos, supervisa las tareas y finalmente realiza la evaluación de los aprendizajes con carácter no solo sancionador o de promoción sino sobre todo formativo.

4. La evaluación de proceso debe articularse sobre procedimientos e instrumentos claros y conocidos que permita verificar los distintos elementos que constituyen el sistema y en su caso tomar las decisiones adecuadas. En todo caso los participantes deben sentirse reconocidos en la evaluación de proceso. 
(Nótese la especial importancia que se concede a la evaluación que aparece reflejada en tres de los cuatro puntos citados)

Por último cabe decir que hay otros rasgos que definen igualmente un modelo de aprendizaje en redes. De esta forma cuando hablamos de un sistema de EAD, de un campus virtual, etc podemos hablar de su carácter participativo en la medida que hayan, o que se establezcan, espacios donde se tengan en cuenta los intereses, las expectativas,... de los participantes, dándose oído a todo tipo de sugerencias y de necesidades.

Lo innovador adquiere un papel importante en la medida en que los recursos y servicios que alberguen al sistema de EAD deben de propiciar la creación de entornos $y$ metodologías nuevas que ofrezcan a lo tecnológico un "valor añadido en lo educativo".

Mención aparte merece la transparencia como rasgo definitorio, no solo de los sistemas tecnológicos de aprendizaje abierto y a distancia, sino de la tecnología digital en su conjunto cuando se utiliza dentro de un contexto de educación o de formación: Lo tecnológico ha de perturbar lo menos posible, y no ha de perturbar nada en el caso óptimo, los aprendizajes añadiendo confusión conceptual a causa de la estructura de los recursos informáticos, telemáticos, o debidos a la terminología utilizada, etc. El horizonte es pues el de una TECNOLOGÍA INVISIBLE cuya presencia pase desapercibida.

La mayor parte de los requisitos de calidad señalados afectan al diseño y a la práctica de sistemas de EAD en su conjunto, o bien han sido incluidos en otros apartados de este trabajo, no obstante algunos de ellos pueden hacer referencia a plataformas o tener repercusiones en características de estos programas:

\section{Requisitos provenientes del diseño de intervención psicoeducativo y curricular}

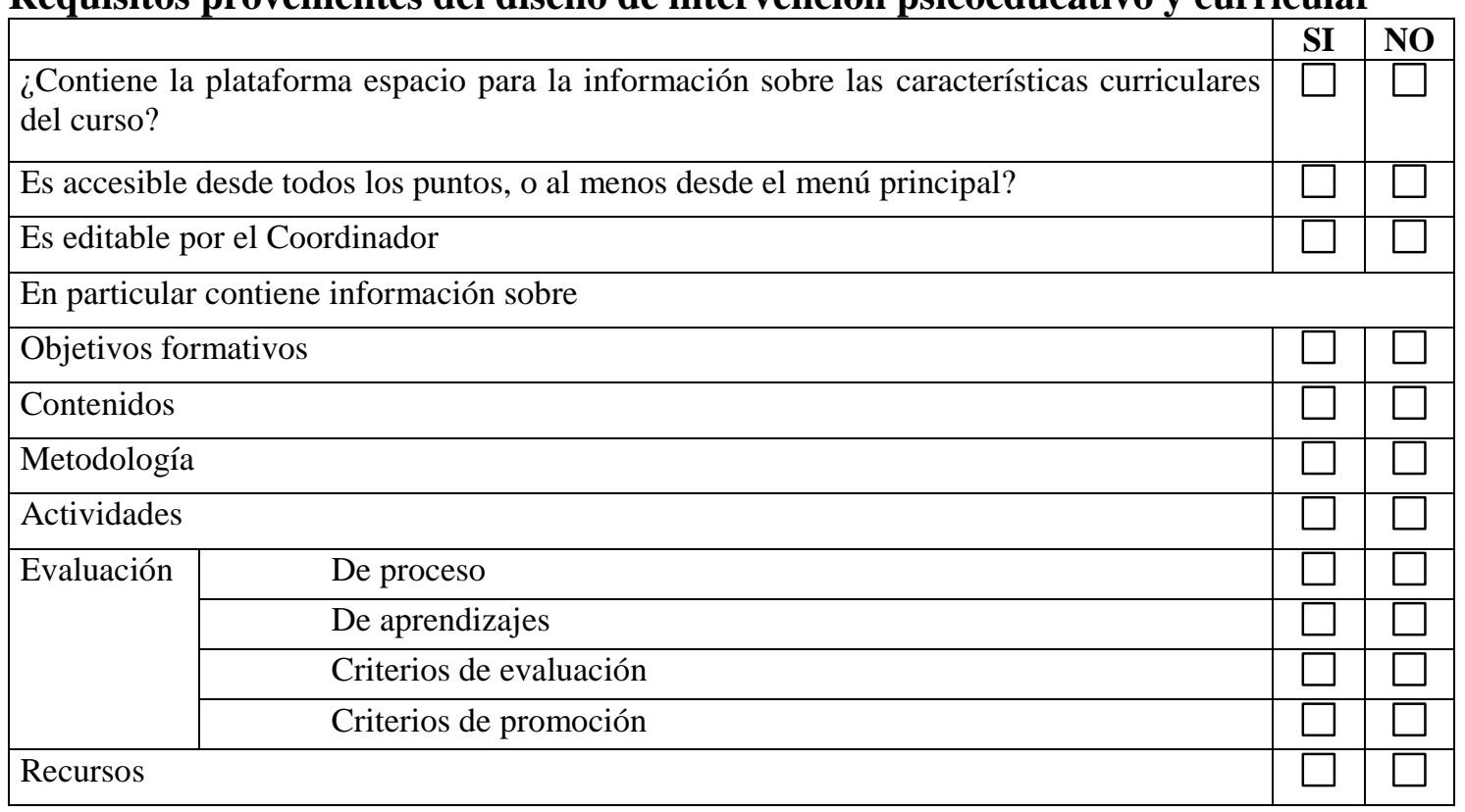




\begin{tabular}{|c|c|c|}
\hline \multicolumn{3}{|c|}{$\begin{array}{l}\text { Un currículo abierto debe contemplar la posibilidad de incluir en la programación adaptaciones a } \\
\text { situaciones especiales, con actividades, evaluaciones, etc. alternativos. También debe contemplar la } \\
\text { posibilidad de tratamientos singulares para alumnos con circunstancias extraordinarias sobrevenidas a } \\
\text { lo largo del curso. }\end{array}$} \\
\hline ¿Contempla la plataforma esta posibilidad? & $\begin{array}{l}\text { SI } \\
\square\end{array}$ & $\begin{array}{l}\text { NO } \\
\square\end{array}$ \\
\hline
\end{tabular}

Presentación del artículo en su edición original: 1 de Octubre de 2003 Fecha de aprobación de su edición original: 15 de Octubre de 2003

Fecha de publicación: 15 de Julio de 2016

Zapata, M. (2016). Sistemas de gestión del aprendizaje - Plataformas de teleformación. RED. Revista de Educación a Distancia, 50. Consultado el (dd/mm/aaaa) en $\mathrm{http}: / / \mathrm{www} . u m . e s / \mathrm{ead} / \mathrm{red} / 50$

\section{Referencias}

Bates, A.W. 1997. Restructuring The University For Technological Change. The Carnegie Foundation for the Advancement of Teaching What Kind Of University? 18-20 June, 1997 London, England

Borrás, I. (1996b). Tecnologías de telecomunicación y educación a distancia en los Estados Unidos. Pixel-Bit. Revista de Medios y Educación, 8.

Borrás, Isabel(1997a).Enseñanza y aprendizaje con la Internet: una aproximación crítica. http://www.doe.d5.ub.es/te/any97/borras_pb/\#capitol7

Chris Smith, Terry Murphy y Tricia Teng (2001). The Perfect Fit: Selecting the Online Learning Environment of Tomorrow. Consortium for Information Technology in Education (CITE). New Brunswick Community College - Saint John Today. April 2001

Daniel, J. (1996). Megauniversities and Knowledge Media. London: Kogan Page.

De Benito Crosetti, Barbara (2000). Herramientas para la creación, distribución y gestión de cursos a través de Internet. Edutec. Revista Electrónica de Tecnología Educativa. 
Núm. 12. /junio 2000 http://edutec.rediris.es/Revelec2/Revelec12/deBenito.html 02/07/03 11:37

Gagne, R. (1975). Essentials of learning for instruction. Hillsdale, Illinois: The Dryden Press.

FEFC (1997). How to Apply for Funding. Bristol: Further Education Funding Council.

Gagne, R. (1985). The contions of learning and theory of instruction. Fourth Edition. New York: Holt, Rinehart and Winston.

Guitert, Montserrat (1998). La Universitat Oberta de Catalunya. Un nuevo modelo universitario. VI JORNADAS UNIVERSITARIAS DE TECNOLOGÍA EDUCATIVA. Tenerife 98. http://www.ull.es/congresos/tecneduc/Guitert.html

Hannafin, M. (1992). Emerging technologies, ISD, and learning environments: critical perspectives. Educational Technology Research and Development, 40(1),

Hiltz, S.R. (1994). The Virtual Classroom: Learning Without Limits via Computer Networks. Norword, NJ: Ablex.

Honey, M., \& Henriquez, A. (1993). Telecommunications and k-12 educators: Findings from a national survey. New York: Center for Technology in Education. (ERIC Document Reproduction Service No. ED 359 923).

IEEE LTSC (1999). "Learning Object Metadata. Working Draft Document 3" desarrollado por el grupo de trabajo número 12 del IEEE LTSC (http://ltsc.ieee.org/doc/wg12/LOMWD3.htm). Traducido por Iolanda Rabascall, Miguel Rodriguez Artacho, Jordi Vivancos Martí. 17/05/00

Johnston, R (1997). Distance learning medium or message. Journal of Further and Higher Education , 21(1), 107-120

Marcelo, C. Puente, D., Talavera, C. y Torres, J. (2001). Formando Teleformadores: Diseño y desarrollo de un curso online utilizando Webct. Comunicación presentada a la II Conferencia Internacional de Tecnologias de Informaçao e Comunicaçao na Educaçao, Braga, Portugal. http://prometeo.us.es/idea/mie/pub/marcelo/Formando\%20Teleformadores.pdf, 02/07/03 11:37

Marcelo, C. et al. (2002). E-Learning Teleformación. Diseño, Desarrollo y Evaluación de la Formación a Través de Internet. Barcelona, Editorial Gestión 2000

McGreal, R., Gram, T.y Marks, T.(2000): A Survey of New Media Development and Delivery Software for Internet-Based

Learning. [http://telecampus.com/developers/environment/index.html] [http://www.eduworks.net/Webnet2000/newmedia.ppt 25/06/03 12:38] 
Pask, G. (1975). Conversation, cognition and learning. Amsterdam and New York: Elsevier.

Pozo, J.I. (1987). Aprendizaje de la ciencia y pensamiento causal. Visor Libros.

Kearsley, Greg (1997) The Virtual Professor: A Personal Case Study. (http://www.pigncispi.com/articles/distance/kearsley-virtualprofessor.htm). En castellano: El profesor Virtual:

Un caso de estudio personal (http://www.pignc-ispi.com/articles/distance/kearsleyvirtualprofessor.htm\#espanol)

Kearsley, G. (1997) A Guide to Online Learning \& Teaching. http://fcae.nova.edu/ kearsley/online.html

Rheingold, H. (1993). Virtual Communities: Homesteading on the Electronic Frontier. Reading, MA: Addison-Wesley.

TéléÉducation NB, 2003. Plates-formes de formation en ligne. http://teleeducation.nb.ca/content/e-learning-environments/plates-formes/index.html 25/06/03 12:43

Vygotsky, L. (1978). Mind in society. Cambridge: Harvard University Press.

Zapata, M. (1997) Redes telemáticas: Educación a distancia y educación cooperativa. Pixel BIT Revista de Medios y Eucación, nº 8, enero 1997. (57-59)

Zapata, M. (1999) INTERNET Y EDUCACIÓN. “Contextos de Educación” número 2. Universidad Nacional de Río Cuarto, Córdoba. Argentina. ISSN: 1514-2655

Zapata, M. (2002). Formación abierta y a distancia a través de redes digitales: Modelos de redes de aprendizaje RED, 1, 6-9. www.um.es/ead/red/ 02/07/03 11:37 